\title{
AC 2008-548: FINITE ELEMENT LEARNING MODULES FOR UNDERGRADUATE ENGINEERING TOPICS USING COMMERCIAL SOFTWARE
}

\section{Ashland Brown, University of the Pacific}

Ashland O. Brown is a professor of mechanical engineering at the University of the Pacific in Stockton, CA. He has held numerous administrative, management and research positions including Program Director, Engineering Directorate, National Science Foundation, Dean of Engineering at the University of the Pacific; Dean of Engineering Technology at South Carolina State University; Engineering Group Manager at General Motors Corporation: and Principal Engineering Supervisor, Ford Motor Company and Research Engineer Eastman Kodak Company. He received his B.S. in Mechanical Engineering from Purdue University and M.S. and Ph.D. in Mechanical Engineering form the University of Connecticut. He has authored over 40 referred and propriety publications in automotive design, finite element modeling of automobile body structures, and photographic film emulsion coating instabilities. His most recent research includes development of innovative finite element tutorials for undergraduate engineering students and vibrational analysis and measurement of human skeletal muscles under stress using laser holography.

\section{Joseph J. Rencis, University of Arkansas}

Joseph J. Rencis is professor and Head of the Department of Mechanical Engineering at the University of Arkansas in Fayetteville. He also holds the Twenty-first Century Leadership Chair in Engineering. From 1985 to 2004 he was professor in the Mechanical Engineering Department at Worcester Polytechnic Institute. His research focuses on the development of boundary and finite element methods for analyzing solid, heat transfer, and fluid mechanics problems. He currently serves on the editorial board of Engineering Analysis with Boundary Elements and is associate editor of the international Series on Advances in Boundary Elements. Currently he serves as the Vice Chair of the ASME Mechanical Engineering Department Heads Committee, Program Chair-Elect of the ASEE Mechanical Engineering Division, and ABET program evaluator. He received the 2002 ASEE New England Section Teacher of Year Award, 2004 ASEE New England Section Outstanding Leader Award, and 2006 ASEE Mechanics Division James L. Meriam Service Award and is a fellow of the ASME. He received a B.S. from Milwaukee School of Engineering in 1980, a M.S. from Northwestern University in 1982, and a Ph.D. from Case Western Reserve University in 1985.

\section{Daniel Jensen, U.S. Air Force Academy}

Dan Jensen is professor of engineering mechanics at the U.S. Air Force Academy where he has been since 1997. He received his B.S. (Mechanical Engineering), M.S. (Applied Mechanics) and $\mathrm{Ph} . \mathrm{D}$. (Aerospace Engineering Science) from the University of Colorado at Bolder. He has worked for Texas Instruments, Lockheed Martin, NASA, and University of the Pacific, Lawrence Berkeley National Lab and MacNeal-Schwendler Corporation. His research includes development of innovative design methodologies and enhancement of engineering education.

\section{Chuan-Chiang Chen, Tuskegee University}

Chuan-Chiang Chen is an assistant professor of mechanical engineering at Tuskegee University. He earned his B.S. degree from National Chiao Tung University, Taiwan, and his M.S. and Ph.D. form the Ohio State University, all in the field of mechanical engineering. He joined the faculty at Tuskegee University in 2002. Dr. Chen's research interest includes acoustics, vibrations, dynamic system modeling, fluid power noise, and acoustic sensor development. His research and educational projects have received support from NSF, DOE, Ford and TVA. He has published ten referred journal articles, conference papers, and technical reports. Dr. Chen was the recipient of Tuskegee University Outstanding Teaching Award in 2006, and Tuskegee University Outstanding 
Service Award in 2007. He is also a member of ASME, ASEE, and SAE. Currently he serves as faculty advisor for the Tuskegee University student section of ASME, and Pi Tau Sigma.

\section{Essam Ibrahim, Tuskegee University}

Essam Ibrahim is professor of mechanical engineering at Tuskegee University. He earned his B.S. degree from Alexandria University, Egypt, M.E. from McMaster University, Canada, and a Ph.D. from Clarkson University all in the field of mechanical engineering. Immediately after completing his Ph.D. requirements, Dr. Ibrahim worked at CFDRC Corporation in Huntsville, Alabama as a Project Engineer. He joined the faculty at Tuskegee University as an assistant professor in 1990. He was promoted to associate professor in 1994 and full professor in 1998. Dr. Ibrahim has research expertise in the field of liquid atomization with applications to fuel injection, spray combustion, propulsion, two-phase flow, and aerosol technology, using analytical CFD methods. His research and educational projects have received support form NASA, NSF, DOE, AFOSR, and ASHRAE. The results of his effort have been documented in over 100 published referred journal articles, conference papers, and technical reports. Dr. Ibrahim has won many honors and awards including: Tuskegee Technology Award, Technology Utilization Program and the Tuskegee University Outstanding Faculty Performance Award for Research.

\section{Vladimir Labay, Gonzaga University}

Vladimir Labay is associate professor and Chair of the Department of Electrical and Computer Engineering at Gonzaga University in Spokane, WA. In 1987 and 1990 Dr. Labay received a B.Sc. (E.E.) and M. Sc. (E.E.), respectively, from the University of Manitoba, Winnipeg, MB. After graduating with a Ph.D. form the University of Victoria in 1995, he remained in Victoria, $\mathrm{BC}$ as a lecturer and research engineer until accepting an assistant professor position at Eastern Washington University in Cheney, WA. In 2007, Dr. Labay was a visiting scholar at SRM University in Chennai, India and has previously held adjunct professorship positions at the University of Idaho, Moscow, ID and at Washington State University, Pullman, WA. His research interests include modeling of and the development of computer-aided design software for $\mathrm{RF} /$ microwave integrated circuit devices used in wireless and satellite communications.

\section{Paul Schimpf, Eastern Washington University}

Paul H. Schimpf received the B.S. E.E. (summa cum laude), M.S.E.E., and Ph.D. degrees from the University of Washington, Seattle in 1982, 1987, and 1995, respectively. Dr. Schimpf began his academic career in 1998, and is currently Chair of the Department of Computer Science at Eastern Washington University in Cheney, WA. His research interests include numerical methods for forward and inverse solutions to partial differential equations, with biomedical applications. Prior to his academic career, Dr. Schimpf was employed as a Senior Principal Design Engineer in the electronics industry, where he enjoyed 15 years of experience developing parallel embedded signal and image processing systems. 


\title{
Finite Element Learning Modules for Undergraduate Engineering Topics using Commercial Software
}

\begin{abstract}
Finite element learning modules have been developed for different undergraduate engineering courses using commercial software. The finite element method (FEM) or finite element analysis (FEA) is a numerical method widely used in industry to analyze and optimize design problems in broad areas of engineering by commercial firms. The primary goals of these learning modules is to provide undergraduate engineering students with new visually oriented insight into the concepts covered in their courses, basic knowledge in finite element theory, and the ability to apply commercial finite element software to typical engineering problems. The learning modules can be integrated into undergraduate courses that include mechanics of materials, vibrations, steady-state/transient heat transfer, fluid dynamics, biometrics, and electromagnetics. The learning modules can also be used in a stand-alone finite element course. Each learning module provides a common step-by-step guide for solving a problem and also includes solution verification. The learning modules will be accessible $24 / 7$ on the World Wide Web later this year.
\end{abstract}

Faculty at six private and publically supported universities collaborated in this research. These faculty and their students have used and assessed the learning effectiveness of these modules. The development, educational, and analysis objectives are discussed for the finite element learning modules. The educational outcomes have been mapped to ABET Criterion 3 Program Outcomes for Engineering Programs ${ }^{41}$ so that an instructor can integrate an exercise into their inhouse ABET assessment process. The primary assessment tool is a survey that students complete after they have used the learning module. The results from the assessment survey are correlated with the students' Myers Briggs Type Indicator (MBTI) and students' learning style. Initial assessment results indicate that the learning modules are well received by the students and enhance the specific learning objectives set forth in each exercise. Correlation with MBTI and Learning Styles show some interesting initial results, but more data and analysis is needed before statistically significant conclusions can be drawn regarding these correlations. In addition, quizzes given before and after the tutorials were used to evaluate the tutorials' effectiveness. The pre- and post-quizzes show that the tutorials are providing good learning experiences for the students and are an effective way for them to assimilate this difficult technical content. Assessment results are being used for continuous improvement of each finite element learning module over the three year duration of this project.

\section{Introduction and Motivation}

The finite element (FE) method is a numerical procedure that is widely used to analyze engineering problems in commercial engineering firms. It has become an essential and powerful analytical tool in designing products with ever-shorter development cycles ${ }^{6-8}$. At most universities teaching all but the most basic FE theory and applications has resided in graduatelevel engineering programs using a number of FE texts ${ }^{15-17}$. In the past consulting firms found that they needed Ph.D. and M.S. engineering graduates to perform engineering analysis of their 
designs, but recently these firms ${ }^{6,8}$ are asking their B.S. and A.A.S. engineering graduates to learn and apply this powerful analysis technique. The fact that the FE method is not taught as a required element in most undergraduate engineering programs means that our graduates are lacking knowledge of the proper use of this tool ${ }^{26,27}$. There are two principle reasons for the persistence of this deficiency:

1. The introduction of new material into the undergraduate curriculum typically requires the removal of other material from the curriculum; material which may be deemed essential by the faculty and ABET. Also, there has recently been a push to reduce credit-hours of programs nationwide.

2. FE coursework has typically been organized around theoretical details that are more appropriate for graduate students who have a more rigorous mathematical education than the typical undergraduate students.

The basic FE method is currently offered as an elective introductive/senior project course in mechanical, civil, and aeronautical engineering programs $s^{1,2,5,9,11}$. However, a more effective instructional methodology may be available to a broader spectrum of students if FEA is integrated through a sequence of required engineering courses ${ }^{3,4,10}$. This would not turn every engineering student into a FE expert, but would teach students how to use the method effectively while avoiding its misuse. The major goal of this work is to educate a broad spectrum of undergraduate engineering students with a basic knowledge of FE theory, along with practical experience in applying commercial FE software to engineering problems. Our engineering graduates' lack of experience in designing structural solutions using numerical computational methods has been noted in the literature ${ }^{26,27}$. This is a level of knowledge and skill that is expected of engineering graduates by the Accreditation Board for Engineering and Technology, Inc. (ABET, Inc.). The 2008-2009 ABET Criteria for Engineering Programs specify in Criterion 3 , item (k): "an ability to use the techniques, skills, and modern engineering tools necessary for engineering practice, 14 . A number of engineering schools have, or are planning to, add FE analysis to their curriculum ${ }^{1-5,10}$, but this is not happening quickly enough to meet the demand of firms competing in the global economy. The finite element exercises developed in this work will provide a valuable resource to engineering instructors throughout the world and can be access $24 / 7$.

Our NSF funded Course, Curriculum, and Lab Improvement (CCLI) proof-of-concept project is aimed at developing FE tutorials or learning modules that can be easily implemented in "traditional" undergraduate engineering courses. The FE learning modules are developed to provide students with preliminary hands-on experience in FE method applications in engineering problem modeling. The models include problem definition, project educational objectives, analysis approach, assumptions, goals, and comparison to hand calculations or experimental data. Each module assumes the student is unfamiliar with the commercial FE software being used and therefore outlines a step-by-step procedure of modeling the exercise problem.

The motivation of this work is to provide undergraduate engineering students with exposure to $\mathrm{FE}$ analysis as a technological tool to enable them to rapidly design optimized solutions to engineering problems. The FE learning modules are targeted at aiding the students' comprehension and grasp of some of the complex topics covered in typical engineering courses. 
The FE graphical results will allow students to engage the material being taught using their visual senses along with their mental ability which will help them visualize critical concepts, i.e., enhance their learning outcomes. The use of FE Software affords the students a means to perform perturbation studies, with relative ease, to increase their understanding. As described in detail in Section 3, this moves students to a higher level in Bloom's Taxonomy ${ }^{20}$.

The FE learning modules have initially been developed in six engineering areas; structural analysis, mechanical vibrations, fluid mechanics, heat transfer, electromagnetics, and biometrics. The modules were evaluated by integrating them into existing courses in the corresponding subject areas. Faculty and students have initially assessed the effectiveness of the modules at thee higher educational institutions: three private Comprehensive Universities: The University of Pacific, and Gonzaga University, and a private Historically Black University (HBCU): Tuskegee University. The project team is composed of experienced and well-qualified engineering educators at these institutions along with an engineering educator and independent evaluators at: the United States Air Force Academy, University of Arkansas, and Washington State University.

\section{Project Goals and Project Objectives}

The project goals and project objectives have been divided into developmental, educational, and assessment. The project developmental goal is to develop FE learning modules in different engineering areas that are easily accessible and require minimal instructor effort. The project developmental objectives to accomplish this goal are as follows:

1. Integrate into Different Courses. Develop FE learning modules can be integrated into different types of undergraduate engineering and introductory finite element courses.

2. Time and Accessibility. Develop FE learning modules that require minimal classroom time to be integrated into a course with minimal instructor preparation, and are easily accessible.

The project educational goal is to provide undergraduate engineering students with understanding of a specific engineering topic and FE theory, along with an ability to apply commercial FE software to typical engineering problems. The educational goal will be accomplished through four project educational objectives based on Bloom's Taxonomy (see Section 3) and ABET Criterion 3 for Engineering Programs as follows:

1. Engineering Topics (Comprehension; $3 a, 3 k$ ). Understand the fundamental basis of engineering topics through the use of finite element computer models.

2. FE Theory (Comprehension; $3 a$ ). Understand the fundamental basis of FE theory.

3. FE Modeling Practice (Application; $3 a, 3 e, 3 k$ ). Be able to implement a suitable finite element model and construct a correct computer model using commercial FE software integrates objectives \#1 and \#2 above.

4. FE Solution Interpretation and Verification (Comprehension and Evaluation; $3 a, 3 e$ ). Be able to interpret and evaluate finite element solution quality, including the importance of verification - integrates objectives \#2 and \#3 above. 
The project educational objectives address three of six Bloom's Taxonomy ${ }^{40}$ levels, i.e., comprehension, applications, and evaluation and future follow up project will address all six. The educational outcomes above were mapped to ABET Criterion 3 Program Outcomes for Engineering Programs so that an instructor can integrate an exercise into their in-house ABET assessment process. The ABET Program Outcomes that are addressed by the project educational objectives include the following:

(a) an ability to apply knowledge of mathematics, science, and engineering;

(e) an ability to identify, formulate, and solve engineering problems, and;

(k) an ability to use the techniques, skills, and modern engineering tools necessary for engineering practice.

A future ABET Program Outcome that will be addressed includes:

(c) an ability to design a system, component, or process to meet desired needs within realistic constraints such as economic, environmental, social, political, ethical, health and safety, manufacturability, and sustainability

The project assessment goal is to accurately and comprehensively assess each educational objective. The assessment goal will be accomplished through two project assessment objectives as follows:

1. Assessment System. Develop and implement a closed loop (iterative) assessment system.

2. Learning Styles. Gain insight into the effectiveness of the FE learning modules across various personality types and Learning Styles.

\section{Pedagogical Foundations of Project}

The pedagogical foundations for this project are based upon the Kolb Learning Cycle $e^{23-25,33}$ and Bloom's Taxonomy ${ }^{20}$. The Kolb Learning Cycle has proved to be an excellent technique to improve student retention of this complex numerical procedure used to analyze engineering problems. The students are provided "Abstract Hypothesis/Conceptual Modules" that begin with the background of the FE method, fundamental mathematics of FE, move through the concept of "stiffness-analysis", one-dimensional direct stiffness analysis of various structures, the topology of the various finite elements, error analysis of FE results, and concludes with how to model engineering problems using this technique. These activities are interlaced with hands-on FE learning modules that begin stating the proposed problem in a manner that is "real-world" in nature. Then the student is supplied with background theory for the analysis they will attempt. The FE learning modules provide specific instructions on how to build the FE model of the problem using this commercial FEA code. The student then performs the analysis. Instead of doing this in a blind manner, the module provides a connection to the abstract theory of FE and asks the student to perturb certain parameters in the model to predict the results a priori. This causes the students to make connections between the modeling techniques and the underlying physics. This focuses in on the "Active Experimentation" part of Kolb's cycle. After the student performs the analysis, they are asked to attempt to explain the differences between the FE modeling and theoretical results. This requires students to engage in the "Reflective Observation" portion of Kolb's cycle. We believe that by designing the learning experiences to 
completely transverse the Kolb cycle, we have fully engaged the students and optimized the potential learning that the FE learning modules provide.

The Kolb model shown in Figure 1 describes an entire cycle around which learning experiences progress Abstract Hypothesis and Conceptualization, Active Experimentation, Concrete Experience, and Reflective Observation.

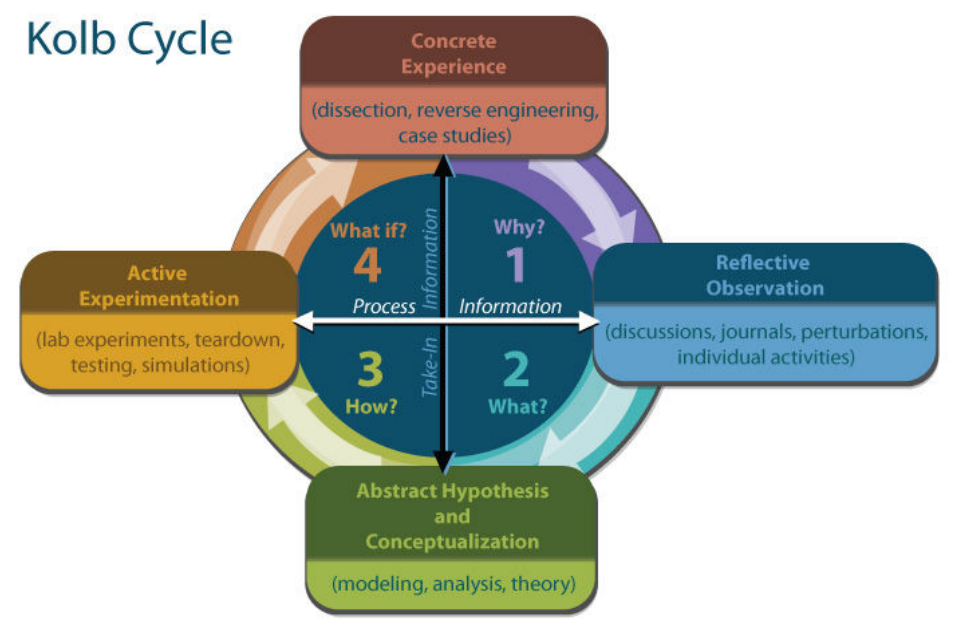

Figure 1. Kolb learning cycle.

The FE learning modules developed in this work are designed to span a spectrum of different manners in which students learn. Felder-Silverman Index of Learning Styles ${ }^{50}$ are composed of four dimensions (active/reflective, sensing/intuitive, visual/verbal, and sequential/global).

Richard M. Felder and Linda K. Silverman formulated the index to assess the learning style of an individual. ALPs are designed to meet the needs of students with a range of Learning Styles. A particular approach to teaching will often favor a certain learning preferences, it is therefore important to conscientiously incorporate a variety of approaches to meet the various learning preferences and styles. As an example, instructors' teaching styles often favor sensing over intuitive Learning Styles or vice versa. The goal of this index is to assist instructors to create ALPs that impact all student Learning Styles effectively. Table 1 shows the Learning Styles categories.

Table 1. Learning Styles categories.

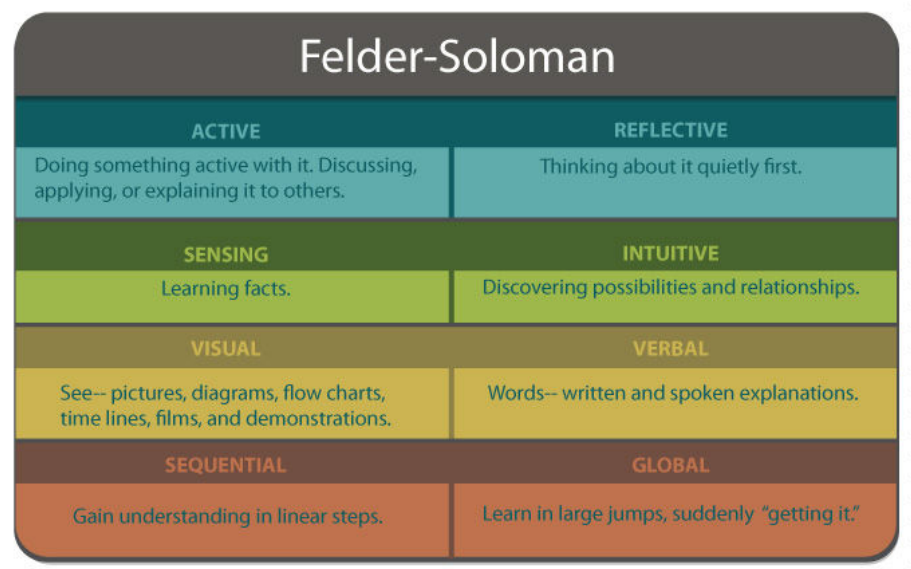




\section{Overview of FE Learning Modules}

The FE learning modules are designed to be applicable for those who have little to no experience using the FE method. Therefore, the problems considered are relatively simple, increasing the likelihood that the students will be able to grasp the correlations between the physical problem and the computational model. The FE learning modules were developed in Microsoft ${ }^{\mathbb{R}}$ Office PowerPoint $^{\circledR}$ and are available in a PowerPoint ppt file and Adobe ${ }^{\circledR}$ Acrobat $^{\circledR}$ pdf file. Each FE learning module was developed using a common template with slides presented as follows:

- Module title, author, author contact information, expected completion time, and references.

- Table of contents

- Project educational objectives based upon Bloom's Taxonomy and ABET Criteria 3 for Engineering Programs.

- Problem description

- Problem analysis objectives

- General steps and specific step by step analysis.

- Viewing the results of the FE analysis.

- Comparison of FE analysis to another technique.

- Summary and discussion.

- Background information on finite element theory.

The FE learning modules have been developed so that they can be integrated into required undergraduate engineering courses that include mechanics of materials, vibrations, biometrics, fluid dynamics, steady-state/transient heat transfer, and electromagnetics. These FE learning modules can also be used in a finite element course depending on the focus of the instructor. The learning modules in the future will be developed to be software independent, but ported initially to one of four commercial FE codes (COSMOSWorks, ANSOFT, MSC.Nastran, or COSMOSFloWorks) that are commonly used in industry. Table 2 summarizes the FE learning modules that have been developed to date. The problem analysis objectives for each FE learning module are summarized in Table 3. The Appendix A contains a summary of the FE learning modules developed in this work to date. The "Curved Beam" FE learning module will be the focus of this paper and is shown in Appendix A.

\section{Formative Evaluation and Summative Evaluation/Assessment of the FE Learning Modules}

The purpose of the formative evaluation of each FE learning module is to implement a process of continuous improvement in the teaching effectiveness of each learning module in each of the three years of this project. The FE learning modules were checked for thoroughness, uniformity, and completeness early into the formative evaluation plan by two members of our research team Joe Rencis and Dan Jensen. The initial assessments verified that the draft modules had text written clearly, uniformly, and pictorials that showed finite element modeling scenes that were easily visualized.

The next part of the formative evaluation was the development of a uniform set of problem analysis objectives that met both ABET Criterion 3 addressed to the correct levels of the Bloom's Taxonomy. 


\begin{tabular}{|c|c|c|c|c|c|c|}
\hline 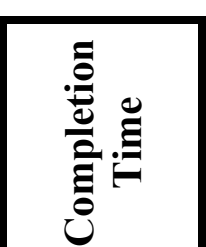 & 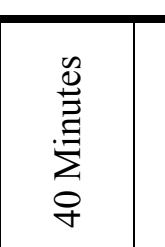 & & 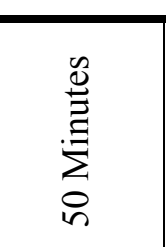 & 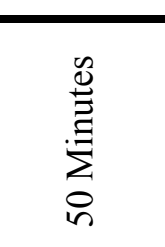 & 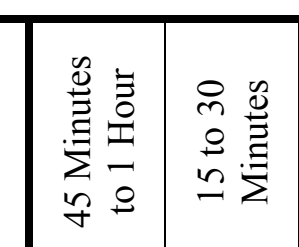 & 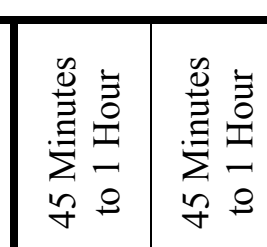 \\
\hline $\mid$ & 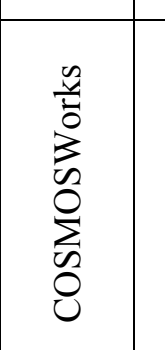 & $\begin{array}{l}\text { 善 } \\
\text { 言 } \\
\frac{8}{8}\end{array}$ & $\begin{array}{l}\text { 善 } \\
\frac{2}{20} \\
\frac{8}{8}\end{array}$ & 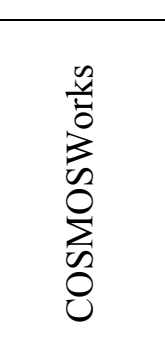 & 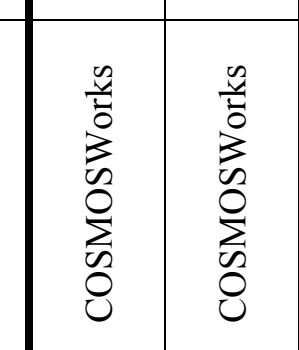 & 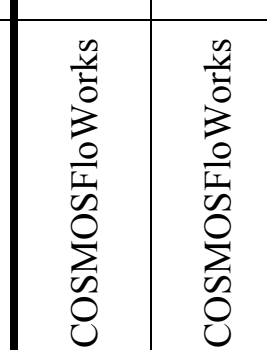 \\
\hline 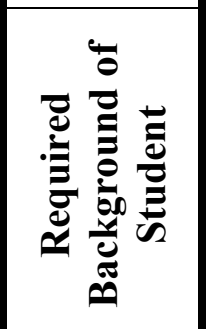 & 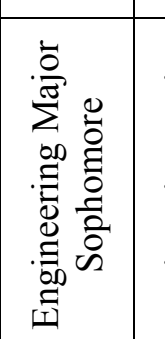 & 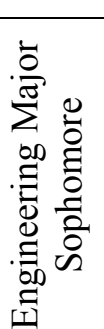 & 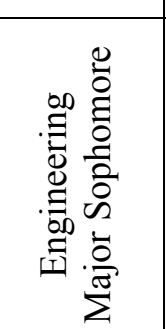 & 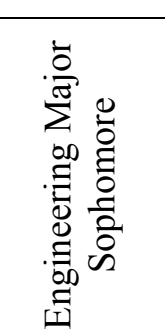 & 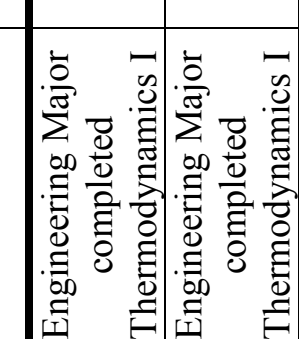 & 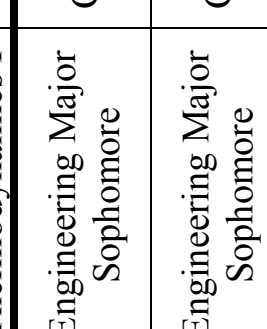 \\
\hline 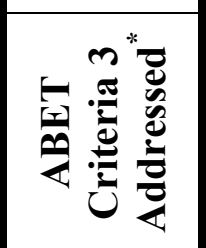 & 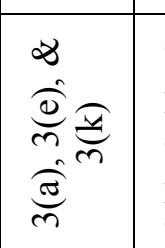 & 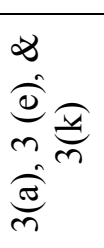 & 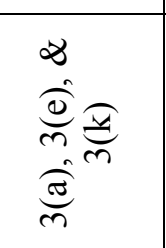 & 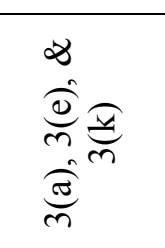 & 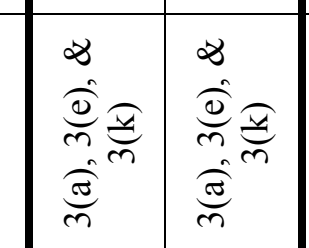 & \\
\hline & & & 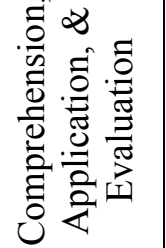 & 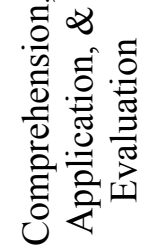 & & \\
\hline 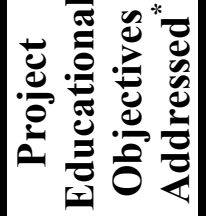 & 薏 & 吾 & 童 & 曾 & 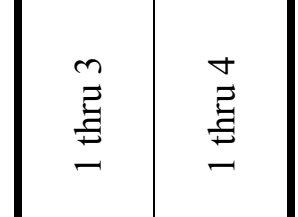 & 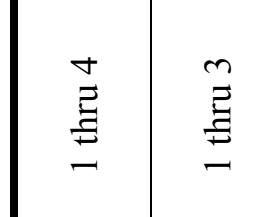 \\
\hline 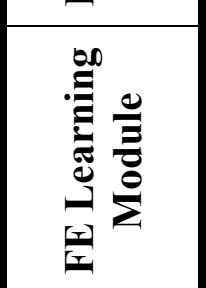 & 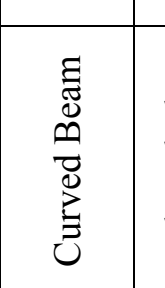 & 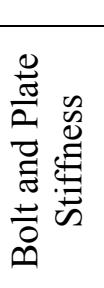 & 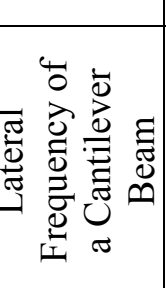 & & & 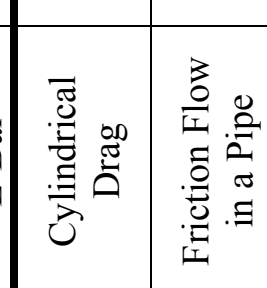 \\
\hline 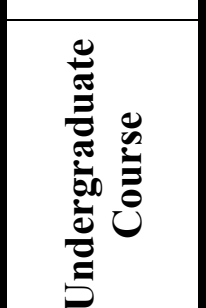 & 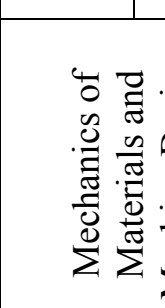 & & & & 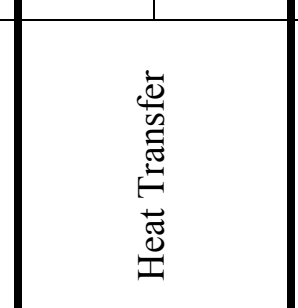 & 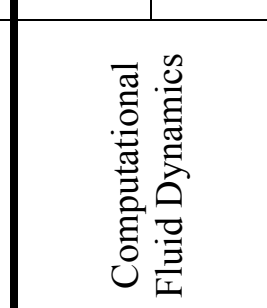 \\
\hline
\end{tabular}




\begin{tabular}{|c|c|c|c|c|}
\hline 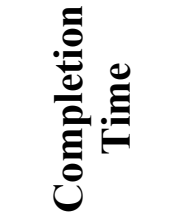 & 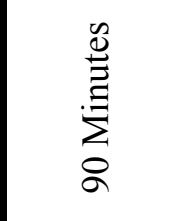 & $\underset{\substack{0 \\
ٍ}}{\stackrel{0}{\Xi}}$ & 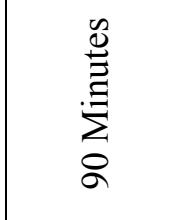 & 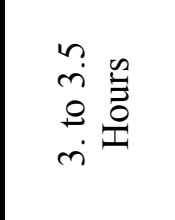 \\
\hline 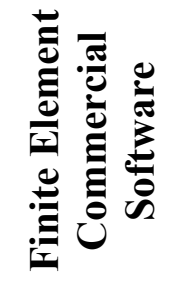 & 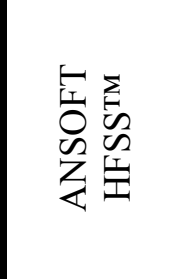 & 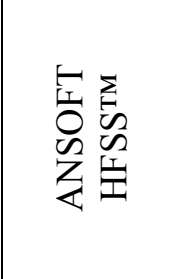 & 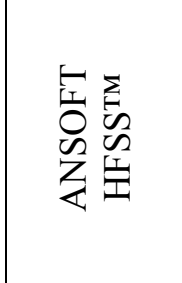 & 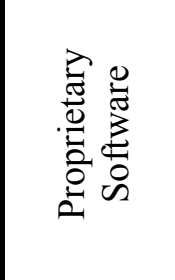 \\
\hline 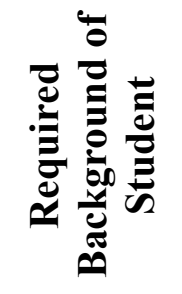 & 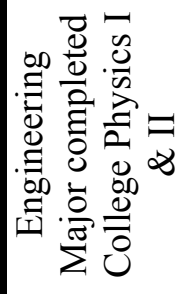 & 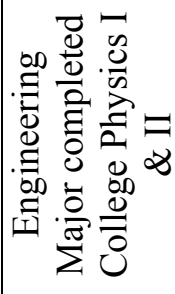 & 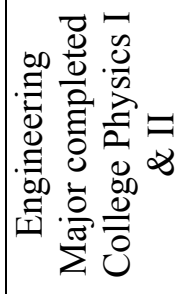 & 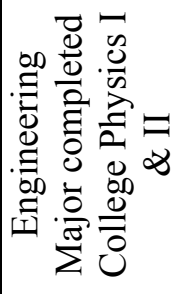 \\
\hline 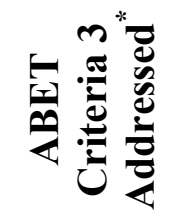 & 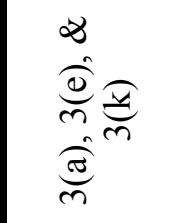 & 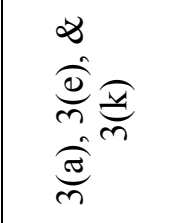 & 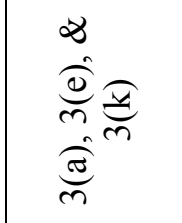 & 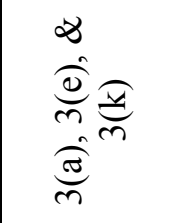 \\
\hline 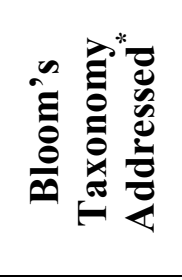 & 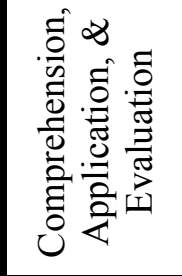 & 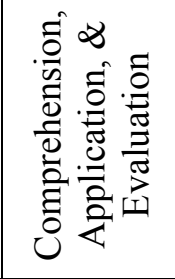 & 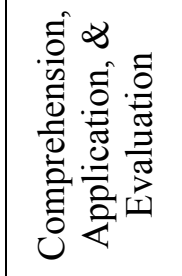 & 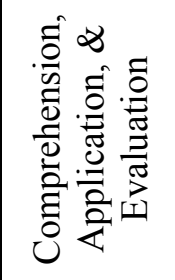 \\
\hline 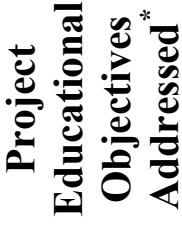 & 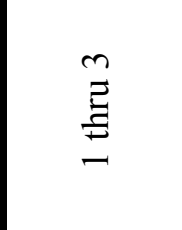 & $\stackrel{n}{\Xi}$ & $\stackrel{m}{\Xi}$ & $\stackrel{\Xi}{\Xi}$ \\
\hline 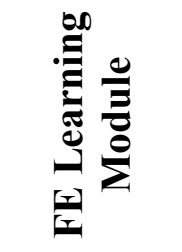 & 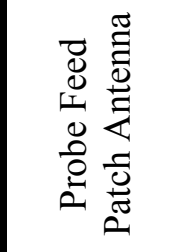 & 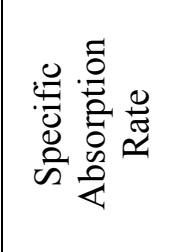 & 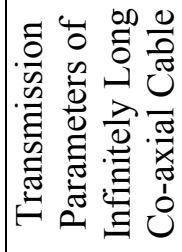 & 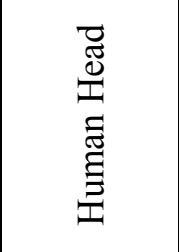 \\
\hline 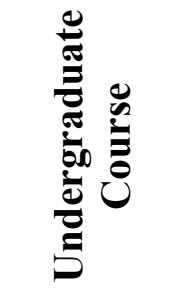 & \multicolumn{3}{|c|}{ 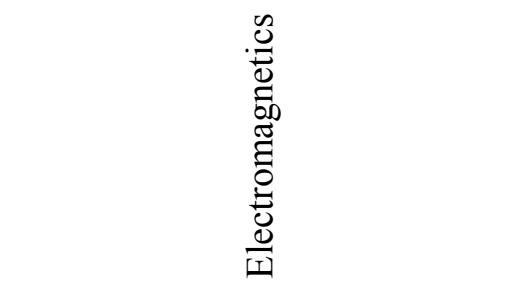 } & 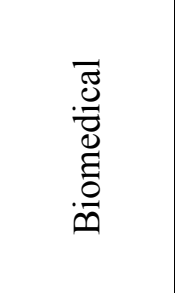 \\
\hline
\end{tabular}




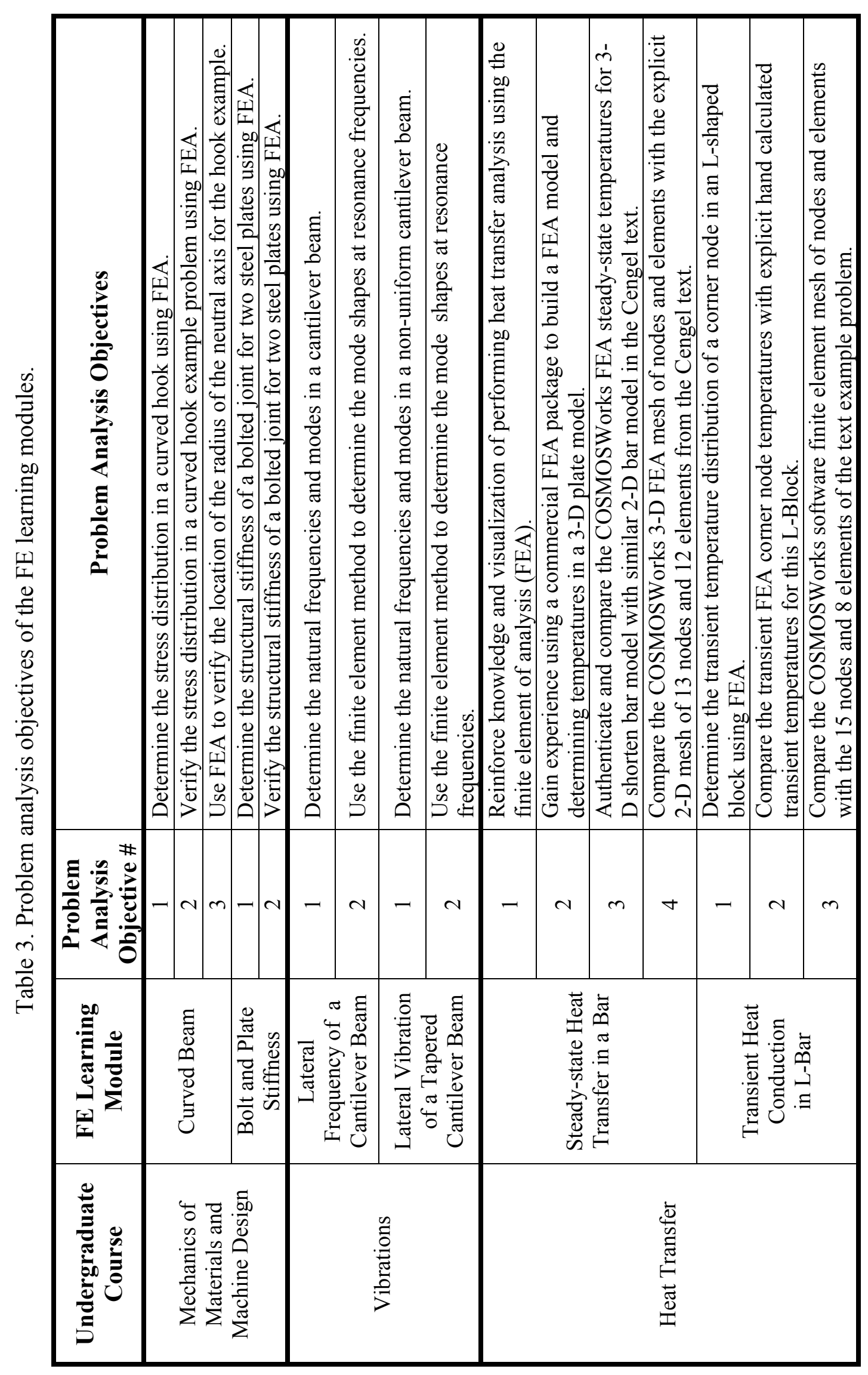




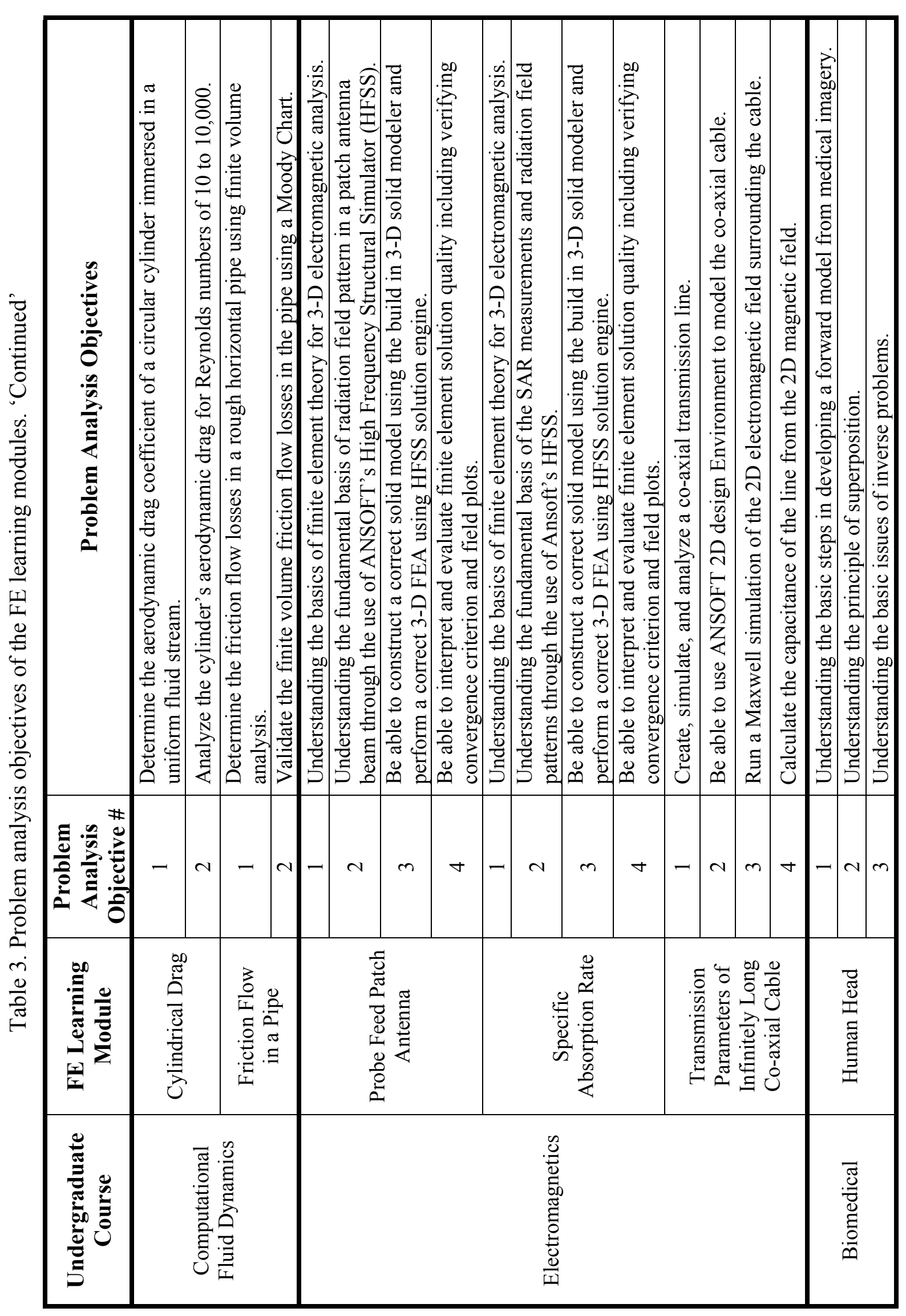


The summative evaluation began in year two of this project by Joe Rencis and Dan Jensen in developing assessment instruments to measure the effectiveness of these learning modules in providing effective learning tools for students enrolled in undergraduate engineering education. A survey assessment instrument and a short fifteen minute quiz were selected as the primary instruments to measure the effectiveness of the FE learning modules in meeting both the project educational objectives and course defined problem analysis objectives to students. The purpose of the analytical objectives is to redefine complex course concepts in a visual manner which triggers one of the MBTI Indices or Learning Styles for the engineering students.

As part of the summative evaluation a set of psychological instruments were also administered to the students to correlate the student Learning Styles, and Myers-Briggs Type Indicators to their acceptance of the learning modules. Adjustments and refinements to each learning module were made annually to improve both their educational effectiveness and to make them more compatible with the MBT Types and Learning Styles of the engineering students.

Our assessment plans for the FE learning modules includes a pattern used in previous engineering educational pedagogical work ${ }^{12-13,20,34,39,44-48}$. The survey assessment instruments and the fifteen minute quizzes were developed by the team of researchers for each engineering course where the learning modules were used.

The student survey instrument questions were based on the four education objectives stated in Section 3 along with specific course analytical objectives developed between the learning module author and the course instructor. The survey used for the curved beam FE learning module is discussed in Section 7. Multiple questions were asked for each educational objective and each analytical objective. The survey questions were developed to follow a common template so that the developers could evaluate how all the finite element exercises satisfied our educational and analytical goals. Questions in the survey instrument did vary slightly based on the nature of the technical area. Table 4 provides an overview of the assessment tools and their primary uses.

Table 4. Assessment tools and their use.

\begin{tabular}{|c|c|}
\hline Assessment Tool & What the Assessment Tool Measures \\
\hline $\begin{array}{l}\text { Pre- and } \\
\text { Post-Quiz }\end{array}$ & $\begin{array}{l}\text { Did the students assimilate course material concepts with a better understanding } \\
\text { of basics in this area? }\end{array}$ \\
\hline Student Survey & $\begin{array}{l}\text { 1. Did students find the courseware easy to use, informative, clear, and } \\
\text { engaging? } \\
\text { 2. Did students believe that the courseware provided a reasonable alternative to } \\
\text { having the content covered in lecture? } \\
\text { 3. Did students find the content illustrated by courseware easy to apply to the } \\
\text { finite element learning modules? } \\
\text { 4. Did the student obtain a better understanding of finite element theory along } \\
\text { with practical experience using commercial finite element software to solve } \\
\text { an engineering problem? }\end{array}$ \\
\hline $\begin{array}{l}\text { MBTI/Index of } \\
\text { Learning Styles }\end{array}$ & $\begin{array}{l}\text { The MBTI is a psychometric instrument designed to sort people into groups of } \\
\text { personality types, and the Index of Learning Styles is a self scoring questionnaire } \\
\text { for assessing preferences on four dimensions of the Felder-Silverman model? }\end{array}$ \\
\hline
\end{tabular}


A typical pre- and post-quiz and student survey will be discussed in Section 7. Each FE learning module has a similar pre- and post-quiz and student survey developed for its content area.

\section{Background and use of MBTI Types of Indicators and Learning Style Data}

A number of researchers have used knowledge of MBTI types to enhance engineering education $^{23,33,44,45}$. In this prior engineering education research it has been shown that different MBTI types respond differently to different pedagogical approaches. In addition, different Learning Styles also prefer content to be delivered in certain formats. The goal of using the MBTI and Learning Styles data is to ensure that the FE learning modules are effective across different personality types (as measured by the MBTI) and across different Learning Styles (as measured by the Felder instrument). Our correlation study will continue to bring these types of nuances to light.

Therefore, the results from the survey are correlated with the students' Myers Briggs Type Indicator (MBTI) and the Felder-Silverman Index of Learning Styles). Each student was required to take the Myers-Briggs Personality located at http://www.humanmetirc.com/cgiwin/JTypes2.asp the Felder-Silverman Index of Learning Styles at http://www4.ncsu.edu/unity/lockers/users/f/felder/public/ILSpage.html. The results from these tests were used for the continuous improvement of the FE learning modules during each academic year to improve them and to enhance student learning.

The MBTI includes four categories of preference. The first category describes whether a person interacts with his or her environment, for people initiating (extroverted) or in a passive (introverted) role. The second category describes how a person processes information. People who process data based upon their senses are referred to sensors, versus people who process data based on the view the information future use who are referred to as intuitor. The sensor versus intuitor's category is seen by most researchers to be the most important of the four categories in terms of education. The third category for MBTI preference attempts to describe the manner in which a person evaluates information. Those who tend to sue a logical "cause and effect" strategy (thinkers) versus those who use a hierarchy based on values or on the manner in which an idea is communicated (feelers). The final MBTI type category indicates how a person makes decisions or comes to conclusions. Those who tend to want to be sure that all data has been thoroughly considered (perceivers) versus those who summarize the situation as it presently stands and makes decisions quickly (judgers). The four letter combination of these indicators are: $\mathrm{E}$ for extrovert, I for introvert, $\mathrm{S}$ for sensor, $\mathrm{N}$ for intuitor, $\mathrm{T}$ for thinker, $\mathrm{F}$ for feeler, $\mathrm{J}$ for judger, and P for perceiver constitute a person's MBTI "type". Table 5, which is adapted from Manuel: Guide to the Development and use of the Myers-Briggs Type Indicator ${ }^{43}$, gives a brief overview of the MBTI categories. 
Table 5. Overview of the MBTI categories ${ }^{43}$.

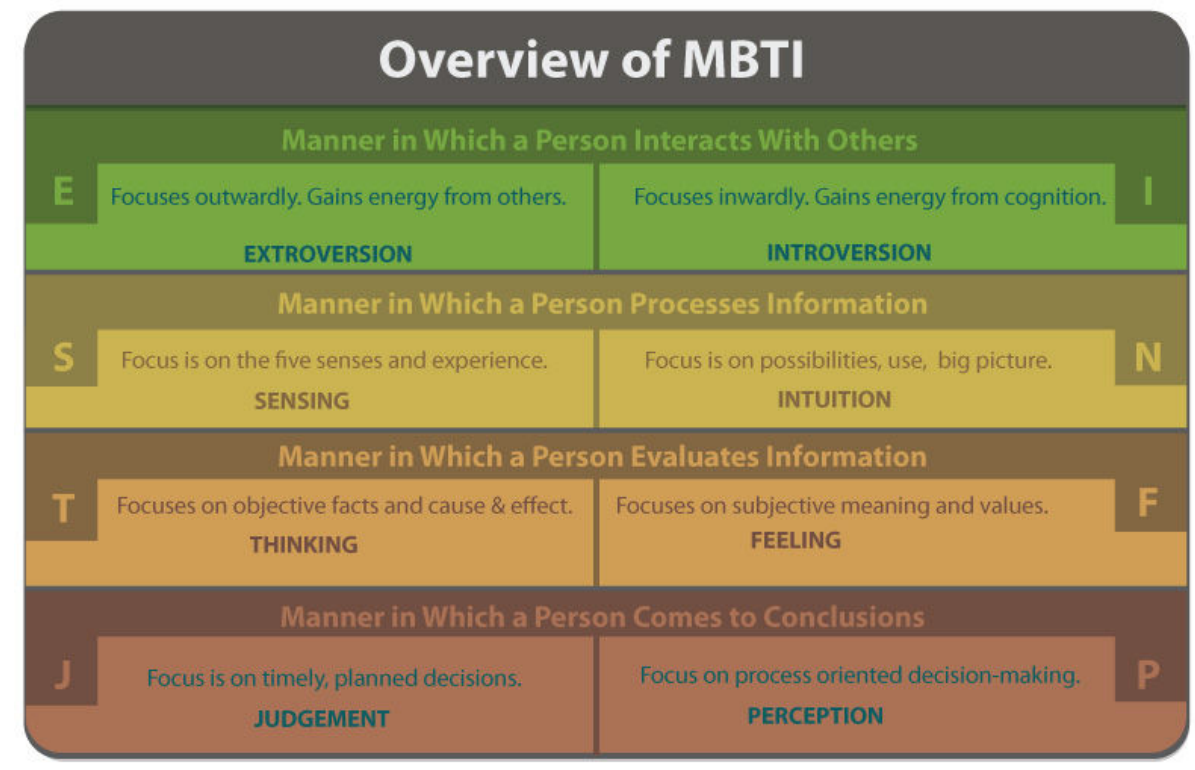

\section{Curved Beam FE Learning Module Assessment Results}

The results of this project can be summarized into four broad categories:

1. Assessment of the FE learning modules effectiveness in providing engineering students with an understanding of specific engineering knowledge and concepts.

2. Assessment of the FE learning modules effectiveness in providing engineering students with the ability to apply commercial FE software to solve typical engineering problems with the finite element method or finite volume method.

3. Assessment of the FE learning modules effectiveness in providing three of Bloom's Taxonomy of comprehension, applications, and evaluation.

4. Assessment of the FE learning modules flexibility to meet the learning requirements of students with broad and Learning Styles and MBTI Indices.

All twelve FE learning modules have been assessed by engineering students at the School of Engineering and Computer Science at University of the Pacific, School of Engineering at Gonzaga University, and the School of Engineering of Tuskegee University during the past two years of this project. The assessment schedule for the twelve learning modules is shown in Appendix B. The assessment program for this project included both formative assessments of the learning modules with their continuous improvement being the main goal. The learning modules were assessed as to whether they met the goals and objective of this research using quantitative and qualitative assessment surveys, fifteen minute quizzes of the subject mater addressed in the learning modules, and comprehensive demographic surveys of the students who completed these learning modules.

The Curved Beam FE learning module in Appendix A is considered. This module was integrated into a machine design course at the University of the Pacific by Ash Brown in the fall 2006 and fall 2007. The quizzes used in fall 2006 and fall 2007 are shown in Figures 2 and Figure 3, respectively. The fall 2006 quiz considered a straight beam and the fall 2007 quiz 
considered a curved beam. The quiz was modified in 2007 to reflect the focus of the FE learning module for a curved beam. A pre-quiz and post-quiz was given to the students for fifteen minutes in the fall 2006 and fall 2007 using the quizzes in Figures 2 and 3, respectively. Table 6 shows the results of the pre- and post-quizzes and Table 7 summarizes the statistical analysis of Table 6. The FE learning module produced increased student knowledge of structural analysis of curved beams by $15.6 \%$ in fall 2006 (a paired T-Test of this data produced a T-Value of 1.17 and a P-Value of 0.138 for this sample size of 9 students) and $23.6 \%$ in fall 2007 (a paired T-Test of this data produced a T-Value of 4.66 and a P-Value $=0.00$ for this sample size of 16 students) as is shown in Tables 6 and 7.

The students were surveyed at the end of the course. The survey assessment tool developed for the Curved Beam FE learning module for fall 2006 and fall 2007 are shown in Figures 4 and 5, respectively. The curved beam survey assessment tool was revised from fall 2006 to fall 2007 to better measure student's comprehension of the project educational objectives and problem analysis objectives. These survey instruments confirmed the perception by students that this activity helped them to understand the concept of a curved beam and assisted them in understanding FE theory. The student's perception shifted from more from Disagree to Agree as is shown in percentages at the bottom of the survey instruments. As an example the students agreed with survey questionnaire $10 \%$ of the time in fall 2006 and $29 \%$ of the time in fall 2007 .

One goal of this research is to create FE learning modules that span the spectrum of learning styles and personality types. As previously noted, we have chosen to measure learning styles using the Felder-Solomon model and are measuring personality preferences using the Myers Briggs Type Indicator (MBTI). In order to gain insight into the effectiveness of the FE learning modules across different learning styles and MBTI types, the pre-quiz and post-quiz results are separated based on these demographic data. Data from the Fall 2007 scores for the "Curved Beam" FE learning module are shown in Table 8. Specifically, we are interested in determining if the "Deltas" [(post-quiz score) - (pre-quiz score)] are statistically different between the pairs of learning styles. In order to determine this, the data is treated as a sample of a theoretical larger population. "Student- $t$ " distributions are used for the statistical analysis as the sample sizes are relatively small. Recall that the Felder/Solomon scale has four learning style pairs (Active vs. Reflective, Sensing vs. Intuitive, Visual vs. Verbal, and Sequential vs. Global). In Table 8, note that the Visual vs. Verbal pair is missing. This is because all of the students in this data set were determined to be "visual" learners. Note that the last three columns in Table 8 refer to "weighted" data. The on-line learning styles survey returns results indicating learning preference for the individual in each of the four categories and also includes a weight or strength for that preference. This allows one to differentiate, for example, between someone who is only slightly "active" over "reflective" in their learning style and someone who very strongly prefers an "active" over "reflective" learning environment. The data in these last three columns were weighted (using a linear interpolation) according to the weights reported from the learning style survey for each student. 
Figure 2. Beam bending basic knowledge (Pre- and post-quiz in Fall 2006 for Curved Beam FE learning module).

Your student ID is used only to match up your bending knowledge prior to completing the Curved Beam FE learning modules and after completion of this module. We will not correlate your knowledge or responses with your name or be used in assessing your grade in MECH 120. Thank you in advance for your cooperation in our research efforts to improve learning here at UOP under this NSF Grant. Prof. Ashland O. Brown.

Student ID:

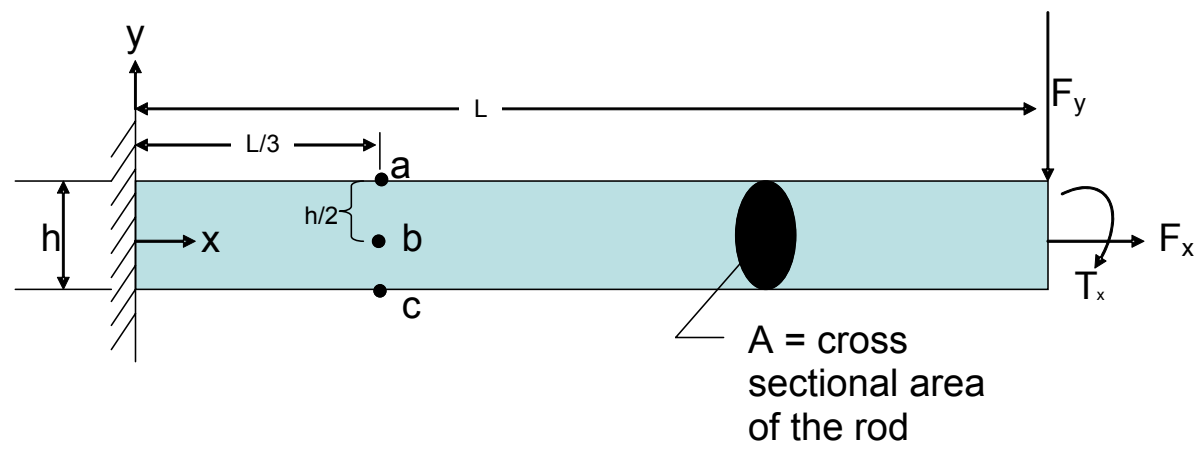

Note:

" $F_{x}$ " is a force in the $\mathrm{x}$-direction

" $T_{x}$ " is a torque about the $\mathrm{x}$-axis

" $\mathrm{F}_{\mathrm{y}}$ " is a transverse (y-direction) force

" $\mathrm{A}$ " is the cross sectional area of the rod

"I" is the $2^{\text {nd }}$ moment of area for the rod

" $\mathrm{h}$ " is the height of the beam

" $\mathrm{M}$ " is the internal bending moment

\section{Circle the best answer}

1. The normal stress at point "a" due to $\mathbf{F}_{\mathbf{y}}$ only is, $\sigma_{a}=$
a) $\frac{T_{x} r}{J}$
b) $\frac{F_{y}}{A}$
c) $\frac{M y}{I}+\frac{F_{y}}{A}$
d) $\frac{M y}{I}$
e) $\frac{F_{x}}{A}$

2. The normal stress at point "b" due to $\mathbf{F}_{\mathbf{y}}$ only is, $\sigma_{b}=$
a) $\frac{F_{y}}{A}+\frac{M y}{I}$
b) $\frac{M y}{I}=0$
c) $\frac{M y}{I} \neq 0$
d) $\frac{T_{x} r}{J}$
e) $\frac{F_{x}}{A}$

3. The loading that produces normal stress due to bending $\left(\sigma_{x}\right)$ is,
a) $F_{x}+T_{x}$
b) $T_{x}$
c) $F_{y}$
d) $F_{x}$
e) $F_{y}+F_{x}$

4. The value of the internal bending moment (M) at point " $a$ " is:
a) $M=\left(\frac{2 L}{3}\right) F_{y}$
b) $M=\left(\frac{L}{3}\right) F_{y}$
c) $M=T_{x}$
d) $M=F_{x}$
e) $M=F_{y}$

5. Regarding the normal stress due to bending at the 3 points "a", "b" and "c":
a) $\sigma_{x}(a)=\sigma_{x}(b)=\sigma_{x}(c)$
b) $\sigma_{x}(a)=-\sigma_{x}(c) \& \sigma_{x}(c)<\sigma_{x}(a)$
c) $\sigma_{x}(a)=-\sigma_{x}(c) \& \sigma_{x}(c)>\sigma_{x}(a)$ 
Figure 3. Beam bending basic knowledge (Pre- and post-quiz in Fall 2007 for Curved Beam FE learning module).

Your student ID is used only to match up your bending knowledge prior to completing the Curved Beam FE learning module and after completion of this module. We will not correlate your knowledge or responses with your name or be used in assessing your grade in MECH 120. Thank you in advance for your cooperation in our research efforts to improve learning here at UOP under this NSF Grant. Prof. Ashland O. Brown

Student ID:
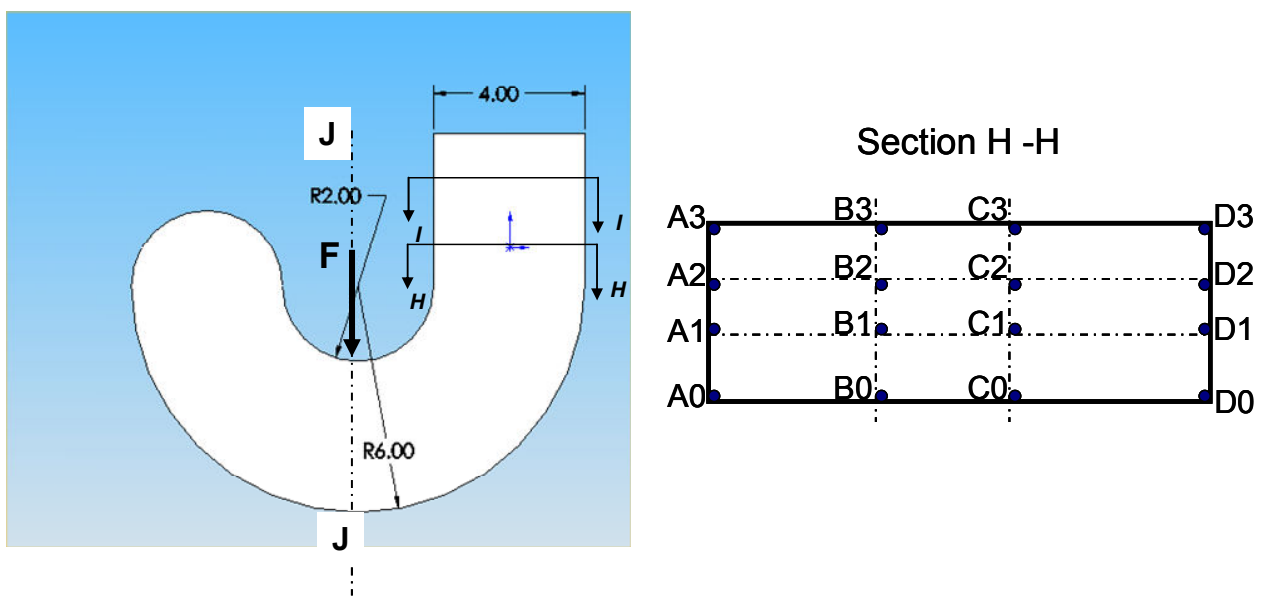

\section{Circle the best answer}

1. The normal stresses at points at A0, A1, A2, and A3 are the same.
a) True
b) False

2. The normal stresses at points at $\mathrm{A} 0$ and $\mathrm{D} 0$ have the relation as follows.
a) $\sigma_{\mathrm{A} 0}>\sigma_{\mathrm{D} 0}$
b) $\sigma_{\mathrm{A} 0}<\sigma_{\mathrm{D} 0}$
c) $\sigma_{\mathrm{A} 0}=\sigma_{\mathrm{D} 0}$

3. The stress at the center of the cross section area is zero.
a) True
b) False

4. The maximum normal stress occurs at the following sections:
a) A0-A3 section
b) D0-D3 section
c) Both A0-A3 and D0 -D3 sections.

5. The shear stress at any points located on the cross-section A0-A3-D0-D3 is zero.
a) True
b) False

6. The maximum stresses on section A0-A3 is equal to its normal stress.
a) True
b) False
c) The question doesn't make any sense.

7. The maximum shear stress occurs on section A0-A3.
a) True
c) False
c) Both answer are wrong.

8. The stress distributions on Section $\mathrm{H}-\mathrm{H}$ and Section $\mathrm{I}-\mathrm{I}$ are the same.
a) True
b) False

9. The stress level of the hook's left portion from section $J-J$ is zero.
a) True
b) False 

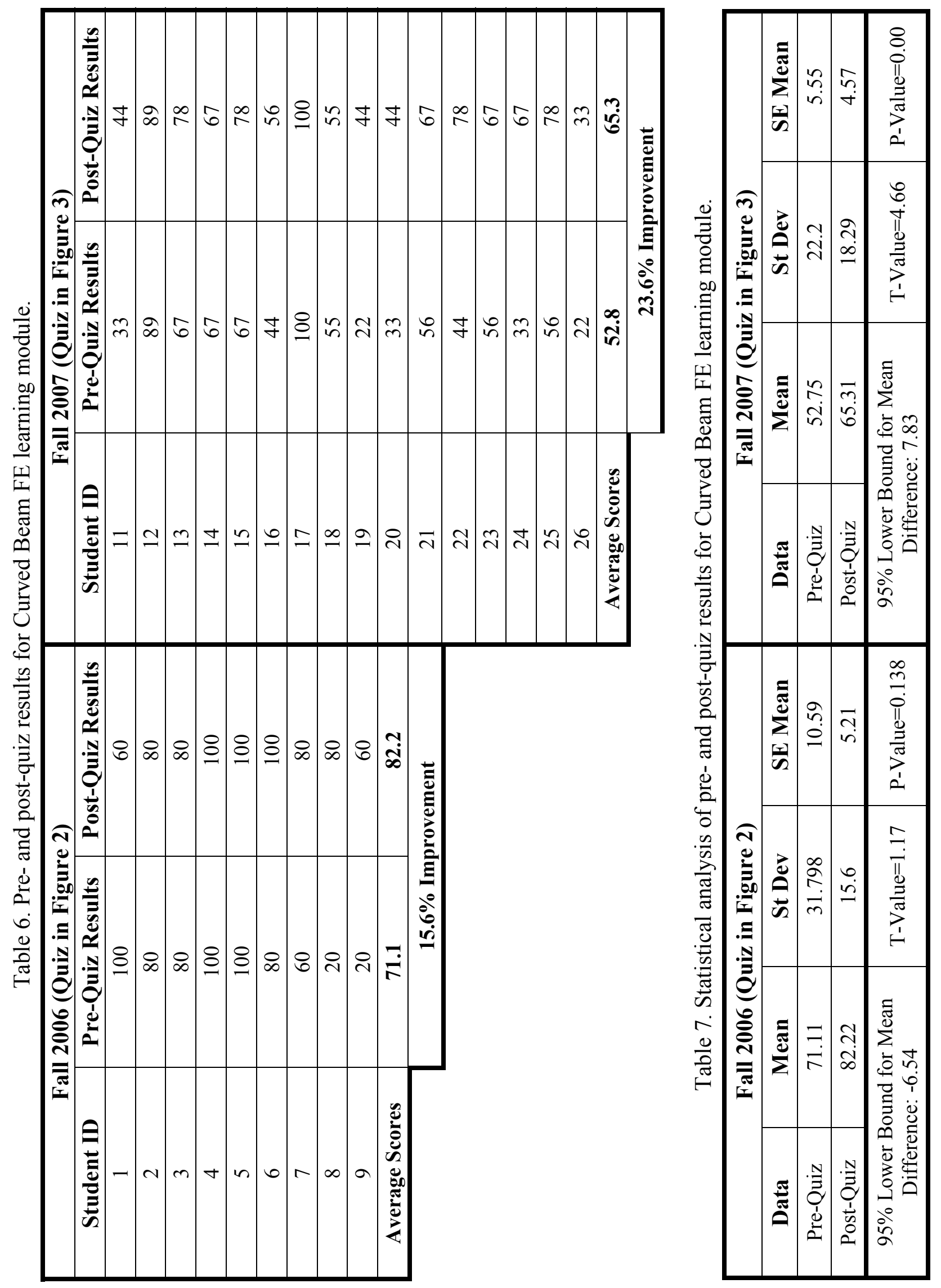

D
$\stackrel{0}{0}$
Dे
$\vec{\omega}$
$\stackrel{0}{\overrightarrow{0}}$
$\stackrel{0}{0}$ 
Figure 4. Student survey and responses in Fall 2006 for Curved Beam FE learning module.

This survey will be used to evaluate and improve active learning activities in this class. Your student ID is used only to match up the results of this survey with others used in the course. Your opinions will be used to improve course learning activities. We will not correlate your survey response with your name or the assessment of any individual. Thank you in advance for your cooperation in our research efforts to improve learning here at the University of the Pacific under this NSF Grant. Prof. Ashland O. Brown

Student ID:

Please put an $X$ in the box below that corresponds to your answer.

\begin{tabular}{|c|c|c|c|c|c|}
\hline Question & Disagree & $\begin{array}{c}\text { Partly } \\
\text { Disagree }\end{array}$ & $\begin{array}{c}\text { Neither } \\
\text { Agree nor } \\
\text { Disagree }\end{array}$ & $\begin{array}{l}\text { Partly } \\
\text { Agree }\end{array}$ & Agree \\
\hline $\begin{array}{l}\text { This activity helped me understand the } \\
\text { topic of "Curved Beam Bending" better. }\end{array}$ & 1 & 1 & 2 & 4 & 1 \\
\hline $\begin{array}{l}\text { Personally seeing and developing the FE } \\
\text { Model was better than a classroom } \\
\text { demonstration. }\end{array}$ & 1 & 1 & & 3 & 3 \\
\hline $\begin{array}{l}\text { This activity will help me do curved beam } \\
\text { bending homework problems. }\end{array}$ & 1 & 3 & 4 & 1 & \\
\hline $\begin{array}{l}\text { This activity helped me understand } \\
\text { bending in a conceptual manner. }\end{array}$ & 1 & & & 7 & \\
\hline $\begin{array}{l}\text { This activity will help me on the next } \\
\text { examination covering this material. }\end{array}$ & 2 & 1 & 6 & & \\
\hline This activity was confusing. & 1 & 3 & 2 & 2 & \\
\hline $\begin{array}{l}\text { I believe this activity was more effective } \\
\text { than using class time for lectures or board- } \\
\text { work. }\end{array}$ & & 2 & 2 & 3 & 1 \\
\hline The activity was a waste of time. & 3 & 1 & 2 & 2 & 1 \\
\hline $\begin{array}{l}\text { This activity increased my interest in } \\
\text { mechanics concepts (like axial, torsion and } \\
\text { bending). }\end{array}$ & 3 & 1 & 3 & 1 & 1 \\
\hline $\begin{array}{l}\text { I liked doing this activity and would like to } \\
\text { learn more on using the Finite Element } \\
\text { method of structural analysis. }\end{array}$ & 2 & & 3 & 2 & 2 \\
\hline Totals & 15 & 13 & 24 & 25 & 9 \\
\hline $\begin{array}{r}\text { Percentage of Students Selecting } \\
\text { Response }\end{array}$ & $17 \%$ & $15 \%$ & $28 \%$ & $29 \%$ & $10 \%$ \\
\hline
\end{tabular}


Figure 5. Student survey and responses in Fall 2007 for Curved Beam FE learning module.

This survey will be used to evaluate and improve active learning activities in this class. Your student ID is used only to match up the results of this survey with others used in the course. Your opinions will be used to improve course learning activities. We will not correlate your survey response with your name or the assessment of any individual. Thank you in advance for your cooperation in our research efforts to improve learning here at the University of the Pacific under this NSF Grant. Prof. Ashland O. Brown

\section{Student ID:}

Please put an $X$ in the box below that corresponds to your answer.

\begin{tabular}{|c|c|c|c|c|c|}
\hline Question & Disagree & $\begin{array}{c}\text { Partly } \\
\text { Disagree }\end{array}$ & $\begin{array}{c}\text { Neither } \\
\text { Agree nor } \\
\text { Disagree }\end{array}$ & $\begin{array}{l}\text { Partly } \\
\text { Agree }\end{array}$ & Agree \\
\hline $\begin{array}{l}\text { This activity helped me understand "curved-beam } \\
\text { bending" in a conceptual manner. }\end{array}$ & 2 & & 3 & 7 & 4 \\
\hline $\begin{array}{l}\text { This activity helped me to understand the stress } \\
\text { distribution in the curved beam. }\end{array}$ & 1 & 2 & 2 & 7 & 4 \\
\hline $\begin{array}{l}\text { This activity helped me to visualize the stress } \\
\text { distribution in the curved beam. }\end{array}$ & 2 & 1 & 1 & 5 & 7 \\
\hline $\begin{array}{l}\text { This activity helped me to have a better } \\
\text { understanding about the deformation of the curved } \\
\text { beam under the concentrated load. }\end{array}$ & 1 & 1 & 6 & 2 & 6 \\
\hline $\begin{array}{l}\text { This activity will help me to design a better } \\
\text { curved beam to undertake a larger load. }\end{array}$ & 2 & 1 & 5 & 4 & 4 \\
\hline $\begin{array}{l}\text { This activity helped to locate the points where the } \\
\text { normal stress is zero. }\end{array}$ & 2 & & 6 & 5 & 3 \\
\hline $\begin{array}{l}\text { Activities like this one doesn't require full } \\
\text { understanding of the finite element theory. }\end{array}$ & & 3 & 5 & 6 & 2 \\
\hline $\begin{array}{l}\text { This activity helped me to create a correct FE } \\
\text { model from 3D CAD model for stress analysis. }\end{array}$ & 1 & 3 & 1 & 9 & 2 \\
\hline $\begin{array}{l}\text { This activity helped me to learn how to apply the } \\
\text { force, add constrains and create meshes for FE } \\
\text { model. }\end{array}$ & 2 & & 1 & 8 & 5 \\
\hline $\begin{array}{l}\text { After completing this activity, I was able to } \\
\text { implement a simple FE analysis using COSMOS. }\end{array}$ & 2 & & 3 & 6 & 5 \\
\hline $\begin{array}{l}\text { This activity was more effective than class time } \\
\text { for lecture or board-work in terms of } \\
\text { understanding the stress distribution. }\end{array}$ & 2 & & 4 & 6 & 4 \\
\hline $\begin{array}{l}\text { The FE analysis method is more useful and } \\
\text { efficient to get all stress information for a } \\
\text { structural member. }\end{array}$ & 1 & 1 & 2 & 7 & 5 \\
\hline $\begin{array}{l}\text { I would like to learn more on using the finite } \\
\text { element method to solve other mechanical } \\
\text { engineering design problems. }\end{array}$ & 1 & 1 & 0 & 5 & 9 \\
\hline Totals & 19 & 13 & 39 & 77 & 60 \\
\hline Percentage of Students Selecting Response & $9 \%$ & $6 \%$ & $19 \%$ & $37 \%$ & $29 \%$ \\
\hline
\end{tabular}


Table 8. Pre- and post-quiz scores separated by learning (Felder-Solomon) style for Curved Beam FE learning module.

\begin{tabular}{|c|c|c|c|c|c|c|c|c|}
\hline $\begin{array}{c}\text { Learning } \\
\text { Style }\end{array}$ & $\mathbf{N}$ & Pre-quiz & Post-quiz & Delta & Stdev & $\begin{array}{c}\text { Weighted } \\
\text { Pre-quiz }\end{array}$ & $\begin{array}{c}\text { Weighted } \\
\text { Post-quiz }\end{array}$ & $\begin{array}{c}\text { Weighted } \\
\text { Delta }\end{array}$ \\
\hline Active & 10 & 46.60 & 61.10 & 14.50 & 12.01 & 47.63 & 60.65 & 13.02 \\
\hline Reflective & 4 & 69.00 & 78.00 & 9.00 & 9.00 & 86.73 & 89.73 & 3.00 \\
\hline Intuitive & 6 & 62.00 & 73.14 & 11.14 & 13.18 & 53.04 & 64.15 & 11.11 \\
\hline Sensing & 8 & 47.13 & 61.13 & 14.00 & 13.57 & 43.28 & 58.38 & 15.10 \\
\hline Global & 4 & 51.00 & 64.40 & 13.40 & 11.50 & 31.64 & 44.29 & 12.64 \\
\hline Sequential & 10 & 55.60 & 67.90 & 12.30 & 11.15 & 59.38 & 70.88 & 11.50 \\
\hline
\end{tabular}

As discussed above, the goal is to determine if the FE learning modules give preference to certain learning styles over others. In order to do this computer statistical confidence intervals are used that tells us the liklehood that the "deltas" for different learning styles are actually different (in a statistically meaningful manner). Table 9 shows the confidence intervals.

Table 9. Confidence intervals for differences between learning (Felder-Solomon) styles for Curved Beam FE learning module.

\begin{tabular}{|c|c|c|}
\hline Learning Style Differences & $\begin{array}{c}\text { Unweighted Confidence } \\
\text { Interval (\%) }\end{array}$ & $\begin{array}{c}\text { Weighted Confidence } \\
\text { Interval (\%) }\end{array}$ \\
\hline Active vs. Reflective & 61.9 & 86.7 \\
\hline Sensing vs. Intuitive & 30.1 & 40.9 \\
\hline Sequential vs. Global & 12.3 & 12.8 \\
\hline
\end{tabular}

The confidence intervals in Table 9 represent the likelihood that the deltas (difference between pre- and post-quiz scores) for pairs of learning styles are statistically different. So, for example, the unweighted confidence interval of $61.9 \%$ for "active" vs. "reflective" learners indicates that there is a $61.9 \%$ likelihood that there is a real (statistically speaking) difference between the deltas for these two opposing learning styles. It is somewhat common to set the threshold of "statistical significance" at a confidence interval of 95\%. As can be seen from Table 9, if this standard is used, there is no statistically significant differences between effectiveness of the FE learning modules for the different learning styles for either weighted or the unweighted cases. This would indicate that the FE learning modules have relatively equal effectiveness across the different learning styles. This is a very positive result as one goal is to avoid significant bias toward one learning style over another.

Although the confidence interval threshold of $95 \%$ is commonly used to indicate statistical significance, it may be informative to consider any occurrences where the confidence interval is greater than $50 \%$. This would indicate that there was greater than $50 \%$ likelihood that one learning style benefited more than another from the FE learning module. If this criterion is used, noting from Table 8 that the "active" learners had a higher delta than the "reflective" learners 
and noting from the first row of Table 9 that the confidence intervals were $61.9 \%$ and $86.7 \%$, respectively, for the unweighted and weighted values the implication is that the FE learning module was more helpful for "active" learners than for "reflective" learners. This result is not surprising as the FE learning modules are, by nature, a very active process where the students participate in each step of building and analyzing the computational model. This being the case, the statistical analysis provides us with an opportunity to refine the FE learning module process in an "active feedback loop" manner. Perhaps the "reflective" learners would be more effectively engaged in the process if, along with the step-by-step FE learning modules, reflective oriented questions were part of the process.

In a manner very similar to what was done for the learning styles, Myers Briggs Type Indicator (MBTI) data is correlated with pre- and post-quiz scores. The goal is the same as with the learning styles data; to determine if certain student groups (in this case certain personality types) benefit differently from the FE learning module process. Recall from Section 6 that the MBTI on-line survey provides students with four letters (either $\mathrm{E}=$ Extrovert or $\mathrm{I}=$ Introvert; either $\mathrm{N}=$ Intuitor or $\mathrm{S}=$ Sensor; either $\mathrm{T}=$ Thinker or $\mathrm{F}=$ Feeler; either $\mathrm{P}=$ Perceiver or $\mathrm{J}=\mathrm{Judger}$ ) that indicate their personality preferences. In addition, weights or strength values for each preference are provided to the students as well. Table 10 has the aggregate pre- and post-quiz scores as well as the deltas (difference between the pre- and post-score) and standard deviations all separated based on MBTI pairs. Note that the $(\mathrm{P}=$ Perceiver or $\mathrm{J}=$ Judger $)$ pair is not included in the table. This is due to the fact that only one student of the fourteen in this data set was a Perceiver. In the same manner as was done for the learning styles, Table 10 includes weighted data as well as unweighted data. The weighted data uses a linear interpolation scheme to include the strength of that particular student's personality typing as provided by the on-line survey output.

Table 10. Pre- and post-quiz scores separated by personality (MBTI) types for Curved Beam FE learning module.

\begin{tabular}{|c|c|c|c|c|c|c|c|c|}
\hline $\begin{array}{c}\text { Personality } \\
\text { Types }\end{array}$ & $\mathbf{N}$ & Pre-quiz & Post-quiz & Delta & Stdev & $\begin{array}{c}\text { Weighted } \\
\text { Pre-quiz }\end{array}$ & $\begin{array}{c}\text { Weighted } \\
\text { Post-quiz }\end{array}$ & $\begin{array}{c}\text { Weighted } \\
\text { Delta }\end{array}$ \\
\hline Extrovert & 11 & 50.45 & 64.64 & 14.18 & 12.46 & 48.23 & 63.32 & 15.09 \\
\hline Introvert & 3 & 52.00 & 63.33 & 11.33 & 0.58 & 49.95 & 61.45 & 11.50 \\
\hline Intuitor & 6 & 57.50 & 72.33 & 14.83 & 11.69 & 56.00 & 70.93 & 14.93 \\
\hline Sensor & 7 & 47.57 & 57.14 & 9.57 & 7.63 & 43.75 & 53.56 & 9.81 \\
\hline Thinker & 10 & 49.90 & 63.40 & 13.50 & 12.83 & 47.25 & 61.36 & 14.11 \\
\hline Feeler & 4 & 53.00 & 66.75 & 13.75 & 5.50 & 50.99 & 66.06 & 15.07 \\
\hline
\end{tabular}

Standard statistical "t-student" analysis is again used to determine the confidence intervals for the three relevant MBTI pairs. Table 11 displays this data. Recall that the confidence interval is the statistical likelihood that there is a difference between the deltas for the different MBTI letter pairs. For example, as can be seen in the Table 11, the likelihood (unweighted) that the Introverted students have a statistically significant delta than do the Extroverts is $53.3 \%$. As 
mentioned above, normally the threshold for statistical significance is set at a confidence interval of $95 \%$. Using this criterion there is no statistical differences, weighted or unweighted, between the different MBTI types. This indicates that, at least for this FE learning module, different MBTI groups do not have significantly more or less benefit from the FE learning modules. In other words, the FE learning modules are not biased toward one student group based on MBTI type. This is a very desirable result!

Table 11. Confidence intervals for differences between personality (MBTI) types for Curved Beam FE learning module.

\begin{tabular}{|c|c|c|}
\hline $\begin{array}{c}\text { Personality Type } \\
\text { Differences }\end{array}$ & $\begin{array}{c}\text { Unweighted Confidence } \\
\text { Interval (\%) }\end{array}$ & $\begin{array}{c}\text { Weighted Confidence } \\
\text { Interval (\%) }\end{array}$ \\
\hline Introvet vs. Extrovert & 53.3 & 61.3 \\
\hline Intuitor vs. Sensor & 63.7 & 60.5 \\
\hline Thinker vs. Feeler & 3.9 & 15.2 \\
\hline
\end{tabular}

However, it may be informative to note that there are four cases where the likelihood of a significant difference is greater than 50\%. Note first from Table 10 that in both weighted and unweighted cases, the Extroverts have a higher delta than the Introverts and the Intuitors have a higher delta than the Sensors. Then from Table 11, note that the confidence intervals for the Exroverts vs. Introverts are $53.3 \%$ (unweighted) and $61.3 \%$ (weighted). The confidence intervals for the Intuitors vs. the Sensors are $63.7 \%$ (unweighted) and $60.5 \%$ (weighted). This data can be used in a "closed loop feedback" fashion to potentially improve the FE learning modules. For example, the slightly higher delta for the Intuitors over the Sensors might lead to a new strategy to bring physical examples of the parts being analyzed into the classroom as part of the modeling experience. The Sensors would likely respond well to this pedagogical technique as they prefer to process knowledge using visual and tactile sensory input as part of the overall experience. This may close the slight gap in deltas between the two MBTI types.

Overall it appears that the Curved Beam FE learning module is not significantly biased toward different student groups as determined by their Felder-Solomon learning styles or their MBTI designations. The small differences observed may be used to revise the FE learning module experience in a closed loop feedback manner. The data considered above represents only one FE learning module. The plan in the future is to analyze data for other FE learning modules in a manner similar to what was done here. Ultimately, the goal is to refine the FE learning modules and overall modeling experience in order to remove any bias toward specific student groups and to maximize the effectiveness of the FE learning modules.

\section{Conclusion}

Our initial conclusion is that FE learning modules properly designed and implemented using "student-friendly" commercial FE software can significantly improve student's knowledge of undergraduate courses in structures, heat transfer, electromagnetics, vibrations, biomedical electromagnetics, and computational fluid dynamics. The FE learning modules must be easily used by both instructors and students to be successfully implemented in a time sensitive undergraduate engineering curriculum. The choice of commercial FE software is key to the student's being able to understand and run the FE software within the reasonable time allocated 
to homework problems during a time-sensitive undergraduate engineering course. We also found that the proper selection of the FE learning module problem is key to the instructor's acceptance of the module in their course. This has to be a team effort between the FE learning module's author and the course instructor for the process to be successful.

\section{Future Work}

The MBTI Indexes and Learning Style data from this work is anticipated will be correlated to the student perceptions of the twelve learning modules in the future. It is anticipated that we will understand what changes in the learning modules will improve a broad spectrum of engineering student's learning of structural analysis, heat transfer, computational fluid dynamics, vibrations, electromagnetics and biometrics. The literature and prior research has shown that engineering students who are composed predominantly of MBTI "N" type students and MBTI" S" type students gain knowledge rapidly from hands-on and visual content learning experiences.

\section{Acknowledgement}

This work is partially supported by the National Science Foundation three year grant DUE CCLI Award Number 0536197.

\section{Bibliography}

1. Graham, L., and Khan, M., "Use of ANSYS and MATLAB in an Introductory Finite Element Course," Computers in Education Journal, Vol. 12, No.1, pp. 32-37, 2002.

2. Chiou, R., Ridenour, S., Lehman, G., Nguyen, T., and Thoonkuzhy, J., "Finite Element Analysis for Design of a Rail Lifter Train," Computers in Education Journal, Vol. 8, No. 4, pp. 50-55 1998.

3. Nesbit, S.N., Comer, J.J., and Van Gulick, L.A., "Finite Element Method in Undergraduate Engineering Education," Computer Applications in Engineering Education, Vol. I, No. 4, pp. 299-305, 1994.

4. Baker, J.R., Capece, V.R., and Lee, R.J., "Integration of Finite Element Software in Undergraduate Engineering Courses," Computers in Education Journal, Vol. 12, No. 2, pp. 10-19, 2002.

5. Matthew, J., and Jahania, S., "Computer Applications for Interdepartmental Engineering Students through Finite Element Method," Computer in Education Journal, Vol. IX, No. 4, pp. 46-48, 1999.

6. Thilmany, J., "FEA in a Snap," Mechanical Engineering, pp. 60-62, July 2001.

7. Mahoney, D.P., "Go with the Flow," Computer Graphics World, pp. 30-36, March 1999.

8. Thilmany, J., “Analyzing up Front,” Mechanical Engineering, Vol. 122, No. 10, pp. 88-91, October 2000.

9. Milton-Benoit, J., Grosse, I.R., Poli, C., and Woolf, B.P., "The Multimedia Finite Element Modeling and Analysis Tutor," Journal of Engineering Education, Vol. 87, No. 5, pp. 511-517, 1998.

10. Sorby, S. Walker, G., Yano, M., Glozman, V., Kochersberger, K., Mathers, J., McKinney, J., Schulman, J., and Young, M., "Modernization of the Mechanical Engineering Curriculum and Guidelines for Computer-Aided Engineering Instruction," Computer Applications in Engineering Education, Vol. 7, I 4, pp. 252-260, 1999.

11. Rencis, J.J., Flory, E., Kwok, P., and Alam, J., "Learning Modules for Finite Element Method on the WorldWide Web," ASEE Computers in Education Journal, Vol. 9, No. 4, pp. 22-28, 1999.

12. Shakerin, S., and Jensen, D., "Enhancement of Mechanics Education by Means of Photoelasticity and the Finite Element Method," International Journal of Mechanical Engineering Education, Vol. 29, No. 4, pp. 307-320, Oct. 2001.

13. Jensen, D., Self, B., Rhymer, D., Wood, J., and Bowe, M., “A Rocky Journey toward Effective Assessment of Visualization Modules for Learning Enhancement in Engineering Mechanics," Journal of Educational Technology \& Society: Special issue on 'Evaluation of Learning Technologies in Higher Education, Vol. 5, No. 3 , pp. 150-162, July 2002.

14. "Criteria for Accrediting Engineering Programs," Effective for Evaluations During the 2005-2006 Accreditation Cycle, ABET Inc., Baltimore, MD, http://www.abet.org. 
15. Reddy, J.N., An Introduction to the Finite Element Method, Second Edition, McGraw-Hill, New York, NY, 1993.

16. Huebner, K.H., Dewhirst, D.L., Smith, D., and Byrom, T.G., The Finite Element Method for Engineers, Fourth Edition, John Wiley \& Sons, Inc., New York, NY, 2001.

17. Chandrupatla, T., and Belegundu, A.D., Introduction to Finite Elements in Engineering, Third Edition, Prentice Hall, Englewood Cliffs, NJ, 2002.

18. Bathe, K.-J., Finite Element Procedures, Prentice-Hall, Englewood Cliffs, NJ, 1996.

19. Kolb, D.A., Experiential Learning: Experience as the Source of Learning and Development, Prentice Hall, Englewood Cliffs, NJ, 1984.

20. Jensen, D., Wood, K., and Wood, J., "Enhancing Mechanical Engineering Curriculum Through the Use of Hands-on-Activities, Interactive Multimedia and Tools to Improve Team Dynamics," International Journal of Engineering Education, Dec 2002.

21. Wood, K., Jensen, D., Bezdek, J., and Otto, K., "Reverse Engineering and Redesign: Courses to Incrementally and Systematically Teach Design," Journal of Engineering Education, Vol. 90, No. 3, pp. 363-374, July, 2001.

22. Wankat, P.C., and Oreovicz, F.S., Teaching Engineering, McGraw Hill, Toronto, 1993.

23. Stice, J.E., "Using Kolb's Learning Cycle to Improve Student Learning," Engineering Education, pp. 291-296, Feb. 1987.

24. Brown, A.O., "Teaching Finite Elements using the Kolb Learning Cycle", Presented at the American Society for Engineering Education Pacific Southwest Section Conference, University of the Pacific, Stockton, CA, April 2004.

25. Brown, A.O., "Undergraduate Finite Element Instruction using Commercial Finite Element Software Tutorials and the Kolb Learning Cycle" Presented at the 2004 ASME International Mechanical Engineering Congress, Anaheim, CA, Nov. 18, 2004.

26. Belytschko, T., Bayliss, A., Brinson, C., Carr, S., Kath, W., Krishnaswarmy, S., Moran, B., and Peshkin, M., "Mechanics in the Engineering First Curriculum at Northwestern University," International Journal for Engineering Education, Vol. 13, No. 6, pp. 457-472, 1998.

27. Brinson, L.C., Belytschko, T., Moran, B., and Black, T., "Design and Computational Methods in Basic Mechanics Courses," Journal of Engineering Education, Vol. 86, No. 2, pp. 159-166, 1997.

28. World Lecture Hall, The University of Texas at Austin, TX, http://www.utexas.edu/world/lecture/.

29. MIT Open Courseware, Massachusetts Institute of Technology, Cambridge, MA, http://ocw.mit.edu/.

30. The National Digital Science Library (NSDL), Funded by National Science Foundation, NSDL, Boulder, CO., http://www.nsdl.org/.

31. Borchert, R., Jensen, D., and Yates, D., "Hands-on and Visualization Modules for Enhancement of Learning in Mechanics: Development and Assessment in the Context of Myer Briggs Types and VARK Learning Styles," Proceedings of ASEE Annual Conference, Charlotte, NC, June 1999.

32. Jensen, D.D., Murphy, M.D., and Wood, K.I., "Evaluation and Refinement of a Restructured Introduction to Engineering Design Course Using Student Surveys and MBTI Data," Proceedings of the ASEE Annual Conference, Seattle, WA, 1998.

33. Kolb, D.A., Experimental Learning: Experience as the Source of Learning and Development, Prentice Hall, Englewood Cliffs, NJ, 1984.

34. Jensen, D.D., Wood, J.J., and Wood, K.L., "Hands-on Activities, Interactive Multimedia and Improved Team Dynamics for Enhancing Mechanical Engineering Curricula," International Journal of Engineering Education, Vol. 19, No. 6, pp. 874-884, 2003.

35. Wood, J., Campbell, M., Wood, K., and Jensen, D., "Enhancing the Teaching of Machine Design by Creating a Basic Hands-on Environment with Mechanical Breadboards," International Journal of Mechanical Engineering Education, Vol. 33, No. 1, pp. 1-25, 2005.

36. Dennis, S., and Jensen, D., "Planetary Gear Set and Automatic Transmission Simulation for Machine Design Courses," Computer Applications in Engineering Education, Vol. 11, Issue 3, pp. 144-155, Jan., 2003.

37. Bowe, M, Jensen, D., Feland, J., and Self, B., "When Multimedia Doesn't Work: An Assessment of Visualization Modules for Learning Enhancement in Mechanics," Proceedings of the ASEE Annual Conference, St. Louis, MO, June 2000.

38. Rhymer, D., and Jensen, D., "An Assessment of Visualization Modules for Learning Enhancement in Mechanics," Proceedings for the ASEE Annual Conference, Albuquerque, NM, June 2001.

39. Wood, J., Winebrener, D., Bartolomei, J., Jensen, D., and Rhymer, D., "Creating a Visually Rich Active Learning Environment for Teaching Mechanics of Materials," Proceedings of the ASEE Annual Conference, Montréal, Canada, June 2002. 
40. Bloom, B.S., Taxonomy of Educational Objectives, David McKay, New York, NY, 1956.

41. "Criteria for Accrediting Engineering Programs: 2008-2009 Accreditation Cycle," ABET Inc., Baltimore, MD, http://www.abet.org/forms.shtml.

42. Felder, R.M., and Spurlin, J., "Applications, Reliability and Validity of the Index of Learning Styles," International Journal of Engineering Education, Vol. 21, No. 1, pp. 103-112, 2005, http://www4.ncsu.edu/unity/lockers/users/f/felder/public/ILSdir/styles.htm.

43. Myers, I.B., and McCaulley, M.H., Manual: A Guide to the Development and Use of the Myers-Briggs Type Indicator, Consulting Psychologists Press, Palo Alto, CA, 1985.

44. Borchert, R., Jensen, D., and Yates, D., "Hands-on and Visualization Modules for Enhancement of Learning in Mechanics: Development and Assessment in the Context of Myers Briggs, Types and VARK Learning Styles," Proceedings of ASEE Annual Conference, Charlotte, NC, June, 1999.

45. Bowe, M., Jensen, D., Feland, J., and Self, B., "When Multimedia Doesn't Work: An Assessment of Visualization Modules for Learning Enhancements in Mechanics," Proceedings of ASEE Annual Conference, St. Louis, June 2000.

46. Rhymer, D., and Jensen, D., "An Assessment of Visualization Modules for Learning Enhancements in Mechanics," Proceedings of ASEE Annual Conference, Albuquerque, NM, June 2001.

47. Wood, J., Winebrener, D., Bartolomei, J., Jensen, D., and Rhymer, D., "Creating a Visually Rich, Active Learning Environment for Teaching Mechanics of Materials," Proceedings of the ASEE Annual Conference, Montréal, Canada, June 2002.

48. Jensen, D., Murphy, M.D., and Wood, K.L., "Evaluation and Refinement of a Restructured Introduction to Engineering Design Course Using Student Surveys and MBTI Data," Proceedings of the ASEE Annual Conference, Seattle, WA, June, 1998.

49. Jensen, D., and Bowe, M., "Hands-on Experiences to Enhance Learning of Design: Effectiveness in a Reverse Engineering/ Redesign Context When Correlated with MBTI and VARK Types," Proceedings of ASEE Annual Conference, Charlotte, NC, 1999.

50. Felder, R.M., and Silverman, L.K., "Learning and Teaching Styles in Engineering Education," Engineering Education, Vol. 78, No. 7, pp. 674-681, 1988.

\section{Appendix A. FE Learning Modules Summary Goals and Status}

\section{Curved Beam FE Learning Module by Prof. Ashland O. Brown}

\section{Module Summary Goals and Status}

1. To reinforce student's knowledge of stress distributions in a curved hook using the finite element analysis (FEA).

2. To verify the stress distribution and the determination of the neutral axis a curved beam.

3. To introduce to undergraduate engineering students the use of (FEA) software.

4. Initially evaluated by undergraduate engineering students at the University of the Pacific.

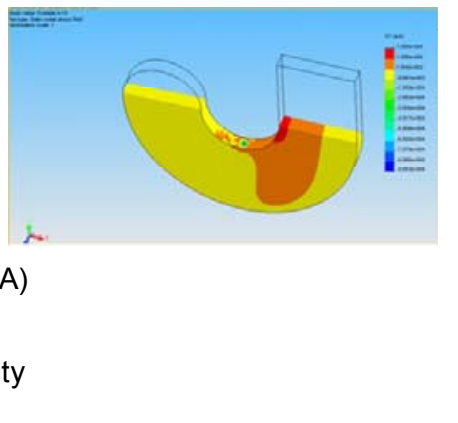




\section{Bolt and Plate Stiffness FE Learning Module by Prof. Ashland O. Brown}

\section{Module Summary Goals and Status}

1. To reinforce student's knowledge of structural stiffness concepts in bolted joint connections

2. To introduce to students the use of finite element analysis (FEA) software for predict bolted joint stiffness for plates.

3. To verify for students the stiffness field in a plate under a bolt using

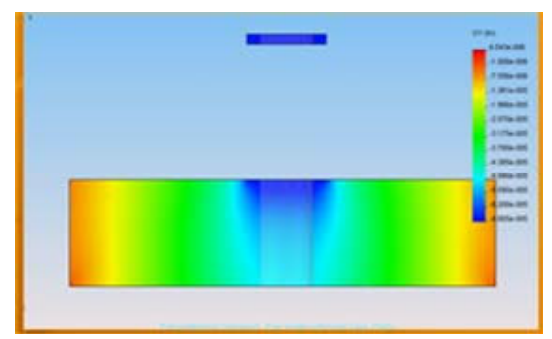
FEA.

4. Initially evaluated by undergraduate engineering students at the University of the Pacific.

\section{Lateral Frequency of a Cantilever Beam FE Learning Module by Prof. Chuan-Chiang Chen}

\section{Module Summary Goals and Status}

1. Reinforce student's understanding of the natural frequencies and modes in a cantilever beam.

2. Introduce to students the use of the finite element method to determine the mode shapes at resonance frequencies.

3. Currently being evaluated by undergraduate students at Tuskegee University.

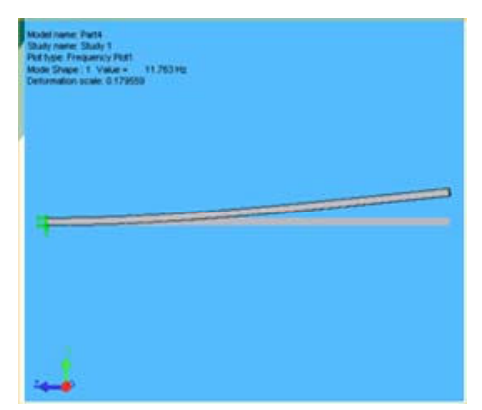




\section{Lateral Vibration of Tapered Cantilever Beam FE Learning Module \\ by Prof. Chuan-Chiang Chen}

\section{Module Summary Goals and Status}

1. Reinforce the student's understanding of the natural frequencies and modes in a non-uniform cantilever beam analysis.

2. Introduce to students the use of the finite element method to determine beam mode shapes at resonance frequencies.

3. Being evaluated with undergraduate engineering students at Tuskegee University.

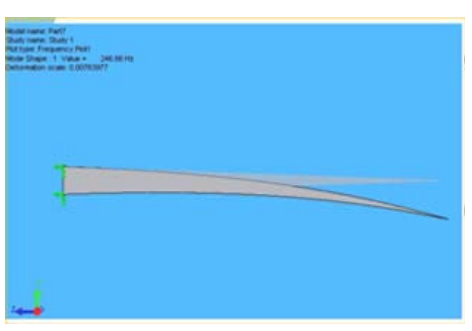

\section{Steady-state Heat Transfer in a Bar FE Learning Module by Prof. Ashland O. Brown}

\section{Module Summary Goals and Status}

1. To reinforce student's knowledge of expected heat transfer results under steady-state analysis.

2. To introduce to undergraduate students the use of finite element heat transfer analysis software.

3. To serve as a comparison with explicit 2$D$ finite difference analysis on the same problem in the text.

4. Has been evaluated initially at by undergraduate engineering students at the University of the Pacific.

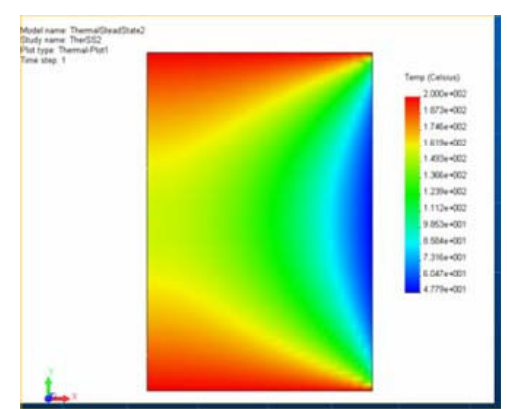




\section{Transient Heat Conduction in L-Bar FE Learning Module \\ by Prof. Ashland O. Brown}

Module Summary Goals and Status

1. Reinforce student's knowledge of transient temperature distributions in an L-Bar using finite element analysis (FEA) software.

2. Compare the transient FEA corner node temperatures to explicit finite difference hand calculated values for the corner node of this problem.

3. Introduce students to the use of FEA software to perform transient heat transfer analysis.

4. Initially evaluated by undergraduate engineering students at the University of the Pacific.

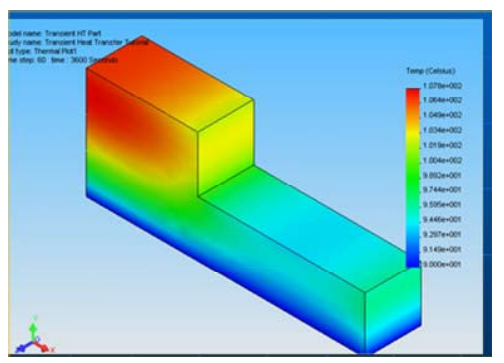

\section{Cylindrical Drag FE Learning Module by Prof. Essam A. Ibrahim}

\section{Module Summary Goals and Status}

1. Reinforce student's knowledge of the aerodynamic drag coefficient of a cylinder immersed in a uniform fluid stream.

2. Introduce to students the use of computational flow dynamics software to determine aerodynamic drag for cylinders in fluid streams with Reynolds numbers from 10 to 10,000 .

3. Currently being evaluated by undergraduate engineering students at Tuskegee University.

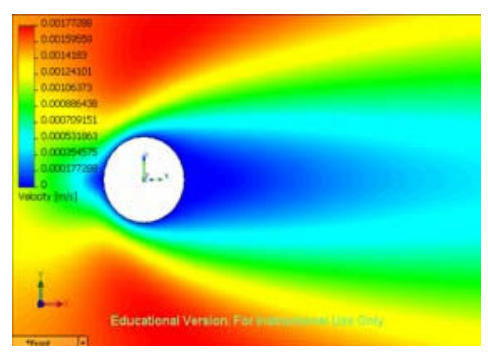




\section{Friction Flow in a Pipe FE Learning Module by Prof. Essam A. Ibrahim}

\section{Module Summary Goals and Status}

1. Reinforce student's learning of determination of friction losses in a rough horizontal pipe using finite volume analysis.

2. Validate the predicted finite volume friction losses in the pipe using a Moody Chart.

3. Introduce to undergraduate engineering students to use of computational flow dynamics software in engineering problems.

4. Currently being evaluated by undergraduate engineering students at Tuskegee University.

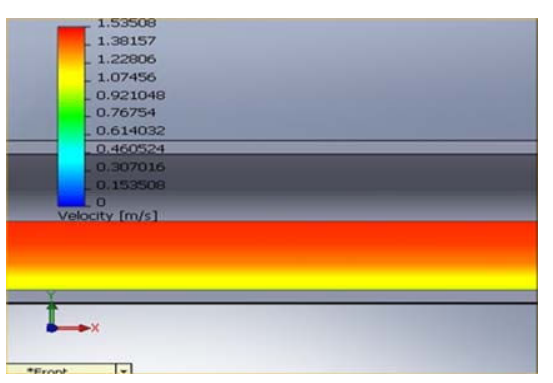

\section{Probe Feed Patch Antenna FE Learning Module by Prof. Vladimir Labay}

Module Summary Goals and Status

1. Reinforce the basics of 3-D Electromagnetics analysis.

2. Reinforce the basis of radiation field pattern in a patch antenna beam through the use of ANSOFT's High Frequency Structural Simulator (HFSS).

3. Introduce students to the construction of a correct solid model using the HFSS solution engine.

4. Currently being evaluated by undergraduate engineering students at Gonzaga University.

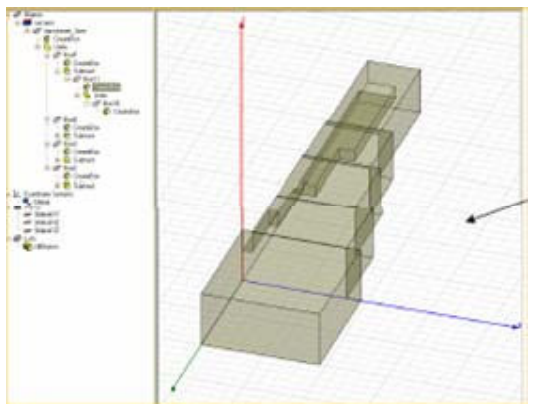




\section{Specific Absorption Rate FE Learning Module \\ by Prof. Vladimir Labay}

Module Summary Goals and Status

1. Reinforce students knowledge of SAR measurements and radiation field patterns through the use of ANSOFT's HSS solution engine.

2. Teach students how to construct 3-D FEA solid models using ANSOFT's modeler.

3. Teach students to interpret and evaluate finite element solution quality including verifying convergence

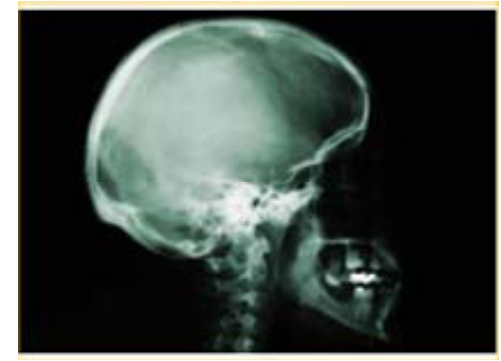
criterion and field plots.

4. Currently being evaluated by undergraduate engineering students at Gonzaga University.

\section{Transmission Parameters of an Infinitely Long Co-Axial Cable FE Learning Module by Prof. Vladimir A. Labay}

\section{Module Summary Goals and Status}

1. Reinforce student's knowledge of simulation and analysis of co-axial transmission lines.

2. Introduce students to use of electromagnetic finite element analysis software.

3. Introduce students to running a Maxwell simulation of the 2D electromagnetic field surrounding a cable.

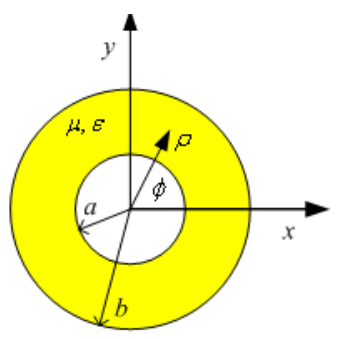

4. Currently being evaluated by undergraduate engineering students at Gonzaga University. 


\section{Human Head FE Learning Module by Prof. Paul Schimpf}

\section{Module Summary Goals and Status}

1. Reinforcing student's knowledge of the basic steps in developing a forward model from medical imagery.

2. Reinforcing student's knowledge of the principle of superposition and the basic issues of inverse problems.

3. Introducing students to the use of finite element analysis in determining solutions to inverse electromagnetic field problems in humans.

4. Initially evaluated by undergraduate engineering students at the University of the Pacific

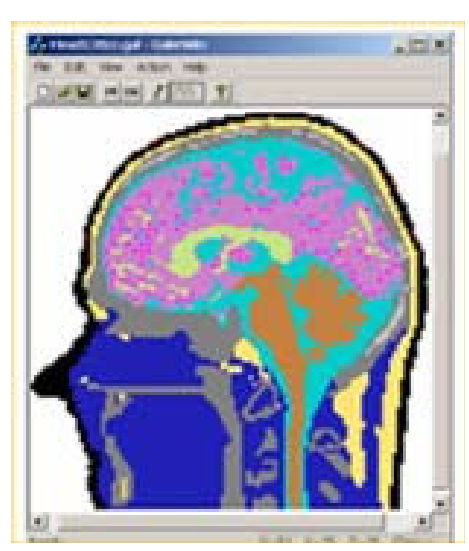


Appendix B. Assessment Schedule for FE Learning Modules
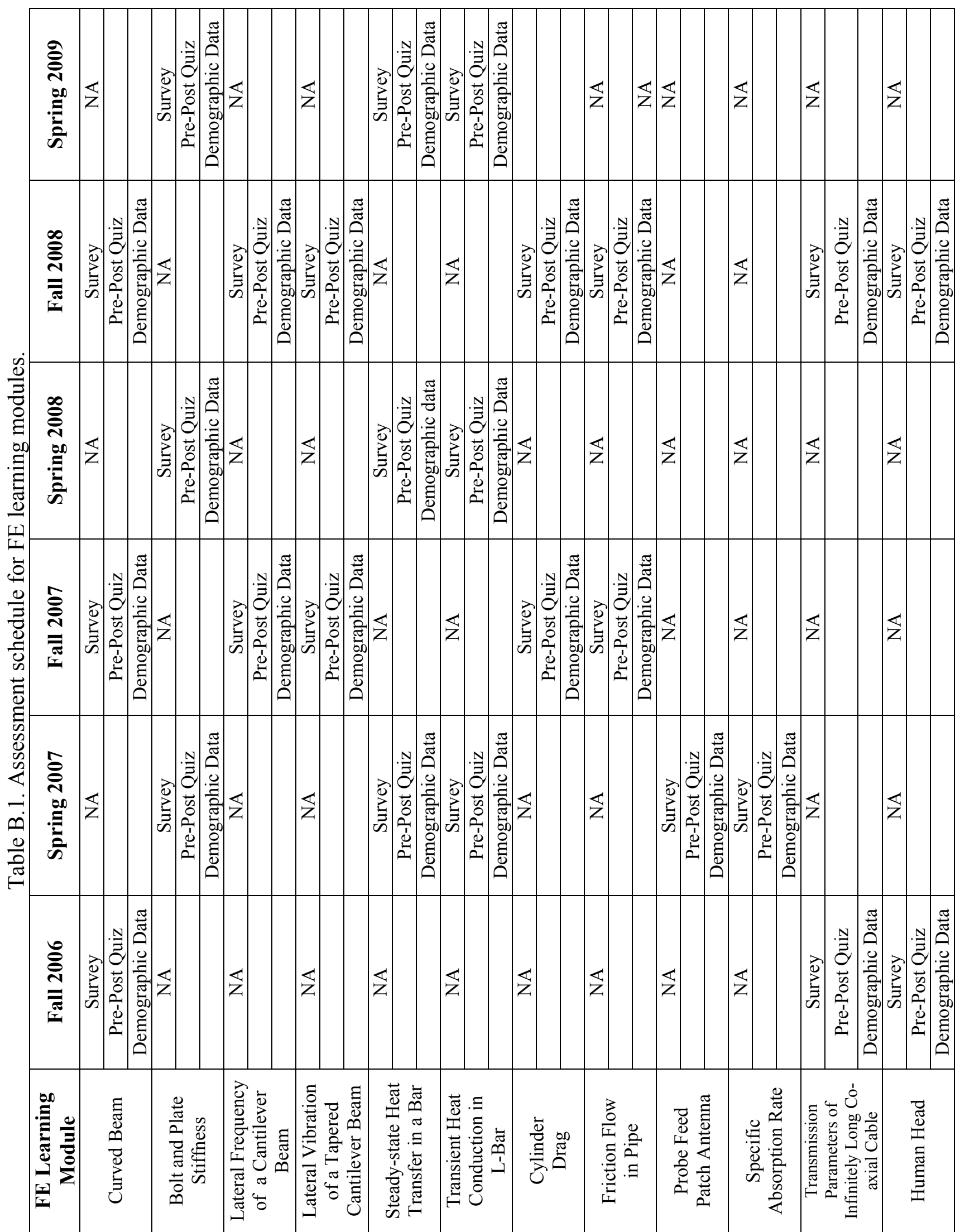